An Advisory Committee Statement (ACS)

Measles and Rubella Elimination Working Group (MREWG)

(1) Notice: New recommendations on measles post-exposure prophylaxis

The chapter in the Measles Outbreak Guideline with recommendations on post-exposure prophylaxis is currently under review. This is due to a recent change in recommendations by the National Advisory Committee on Immunization (NACl) on the indications, dosage and administration of Measles Immune globulin (Ig) post-exposure prophylaxis.

Please refer to NACl's New recommendations on measles post-exposure prophylaxis published September 2018 in the Canada Communicable Disease Report (CCDR).

\title{
GUIDELINES FOR THE PREVENTION AND CONTROL OF MEASLES OUTBREAKS IN CANADA
}

ENDORSED BY THE COUNCIL OF CHIEF MEDICAL OFFICERS OF HEALTH (CCMOH) ON NOVEMBER 2ND, 2012

\section{TABLE OF CONTENTS}

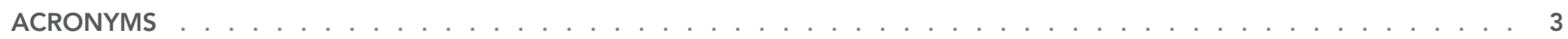

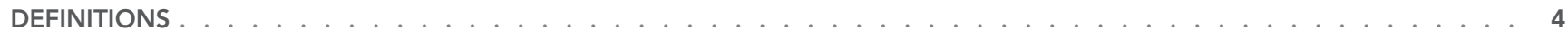

EXECUTIVE SUMMARY . . . . . . . . . . . . . . . . . . . . . . . . . . . . . . . 6

1. INTRODUCTION . . . . . . . . . . . . . . . . . . . . . . . . . . . . . . . . . . . . . . . . . . 7

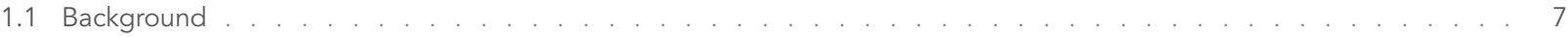

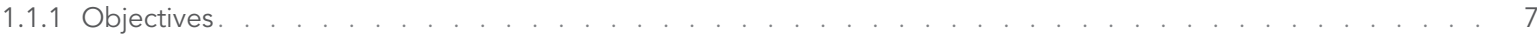

2. EPIDEMIOLOGY OF MEASLES IN CANADA . . . . . . . . . . . . . . . . . . . . . . . . . . . . . 8

2.1 Pre-elimination . . . . . . . . . . . . . . . . . . . . . . .

2.2 Post-elimination . . . . . . . . . . . . . . 9

2.3 Measles outbreaks in Canada . . . . . . . . . . . . . . . . . . . . . . . . . . . . 9

3. SURVEILLANCE AND REPORTING . . . . . . . . . . . . . . . . . . . . . . . . . . . . . . 11

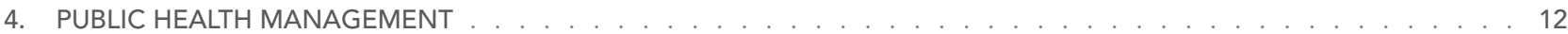

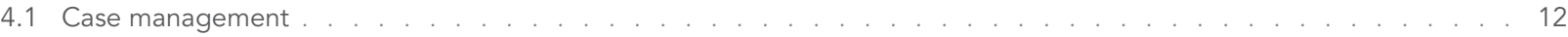

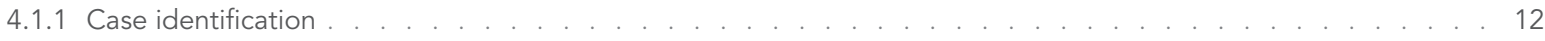

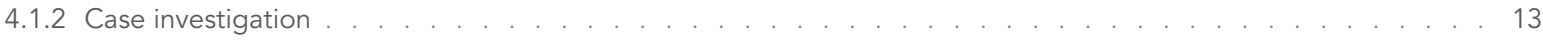

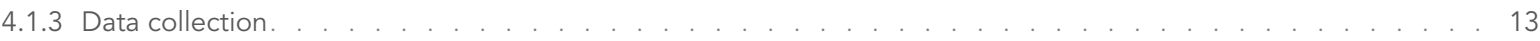

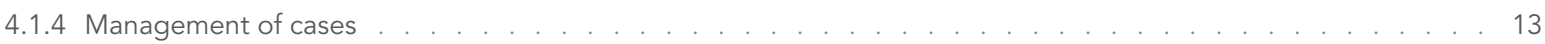

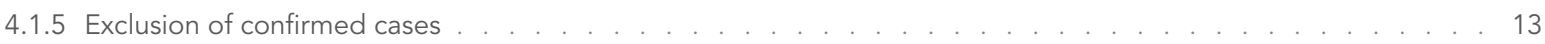

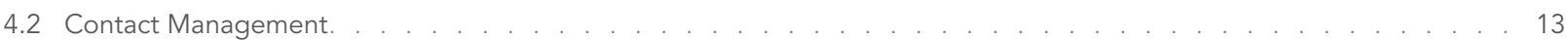

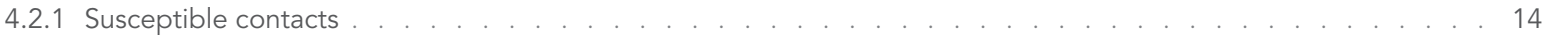

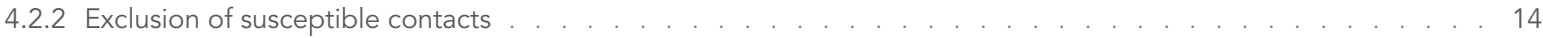

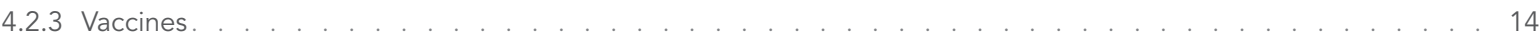

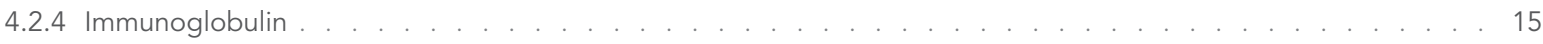

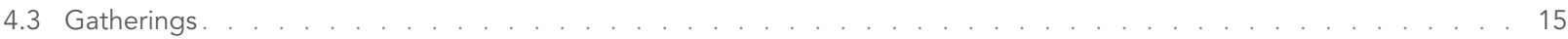




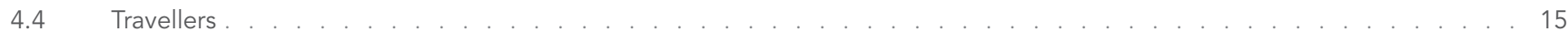

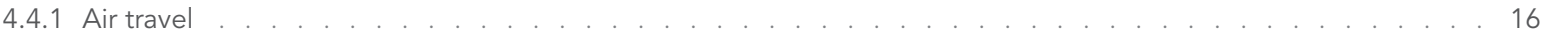

4.4.2 Marine travel on cruise ships . . . . . . . . . . . . . . . . . . . . . . . . . . . . . . . . . . 16

4.4 .3 Other travel modalities . . . . . . . . . . . . . . . . . . . . . . . . . . . . . . . . 17

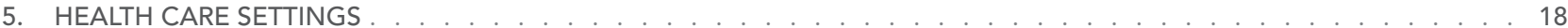

5.1 Infection prevention and control measures for suspected or confirmed measles . . . . . . . . . . . . . . . . 18

5.1.1 Management of healthcare workers exposed to cases. . . . . . . . . . . . . . . . . . . . . . . . . . . .

5.1 .2 Management of patients exposed to cases. . . . . . . . . . . . . . . . . . . . . . . 19

6. LABORATORY GUIDELINES FOR THE DIAGNOSIS OF MEASLES . . . . . . . . . . . . . . . . . . . . . . . . . . 20

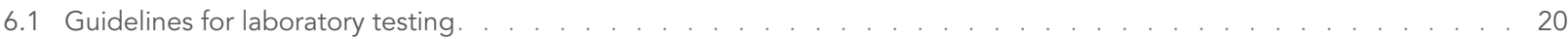

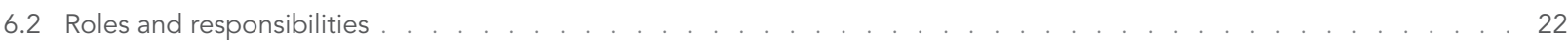

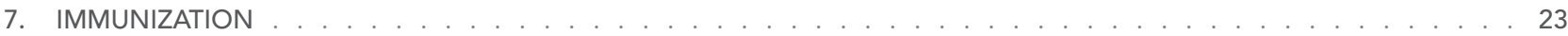

$7.1 \mathrm{NACl}$ recommendations on the use of the measles vaccine $\ldots \ldots \ldots$

7.2 Immunization programs in Canada . . . . . . . . . . . . . . . . . . . . . . . . . . . . . . . . . . . . . . . . . . . . . . . .

7.3 Vaccine supply . . . . . . . . . . . . . . . . . . . . . . . . . . . . . . . . . . . . . . . 24

7.3.1 Measles-containing vaccine in Canada . . . . . . . . . . . . . . . . . . . . . . . . . . . . . 24

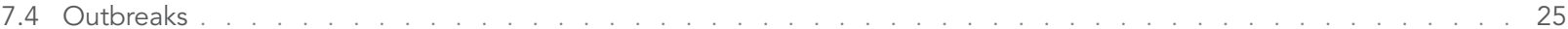

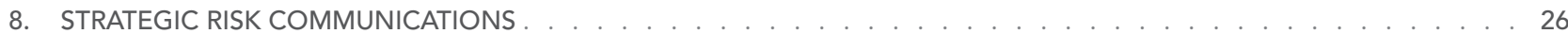

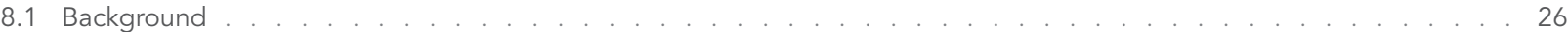

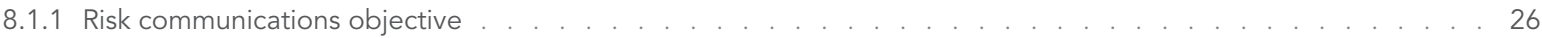

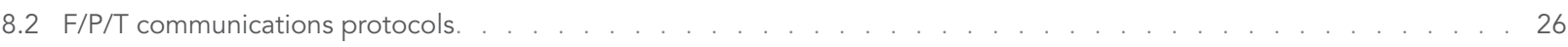

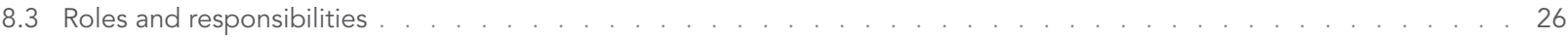

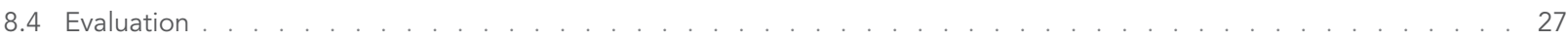

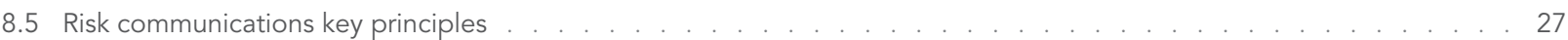

9. ANALYZE THE OUTBREAK . . . . . . . . . . . . . . . . . . . . . . . . . . . . . . . . . . . . . . . . . . . . 29

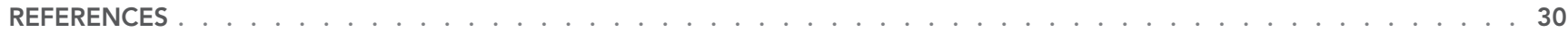

APPENDIX A. PERSONS INVOLVED IN DEVELOPING THE GUIDELINES . . . . . . . . . . . . . . . . . . . . . . . . . . 32

APPENDIX B. PROVINCIAL/TERRITORIAL LEGISLATURES FOR REPORTING COMMUNICABLE DISEASES . . . . . . . . . . . . 33

APPENDIX C. FEDERAL/PROVINCIAL/TERRITORIAL MEASLES REPORTING REQUIREMENTS . . . . . . . . . . . . . . . . . 34

APPENDIX D. NATIONAL MEASLES CASE REPORT FORM . . . . . . . . . . . . . . . . . . . . . . . . 36

APPENDIX E. SAMPLE MEASLES CASE INVESTIGATION FORM. . . . . . . . . . . . . . . . . . . . . . . . . 37

APPENDIX F. RECOMMENDATIONS FOR THE MANAGEMENT OF MEASLES IN HEALTHCARE SETTINGS . . . . . . . . . . . . . 40

APPENDIX G. ALGORITHMS FOR HEALTH CARE SETTINGS . . . . . . . . . . . . . . . . . . . . . . . . 43

APPENDIX H. LABORATORY GUIDELINES FOR THE DIAGNOSIS OF MEASLES . . . . . . . . . . . . . . . . . . . . . . . . . 46

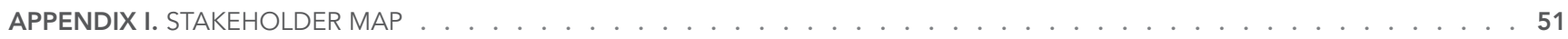

APPENDIX J. MESSAGE FRAMING EXAMPLE . . . . . . . . . . . . . . . . . . . . . . . . . . . 52 


\section{ACRONYMS}

\begin{tabular}{|c|c|}
\hline ACE & Advisory Committee on Epidemiology \\
\hline AlIR & airborne infection isolation room \\
\hline $\mathrm{CCMOH}$ & Council of Chief Medical Officers of Health \\
\hline CFEP & Canadian Field Epidemiology Program \\
\hline $\mathrm{CIC}$ & Canadian Immunization Committee \\
\hline CIG & Canadian Immunization Guide \\
\hline CIRID & Centre for Immunization and Respiratory Infectious Diseases \\
\hline CNDSS & Canadian Notifiable Disease Surveillance System \\
\hline CNPHI & Canadian Network for Public Health Intelligence \\
\hline CMRSS & Canadian Measles and Rubella Surveillance System \\
\hline CRS/I & congenital rubella syndrome / infection \\
\hline CSF & cerebrospinal fluid \\
\hline EIA & enzyme immunoassay \\
\hline $\mathrm{F} / \mathrm{P} / \mathrm{T}$ & Federal/Provincial/Territorial \\
\hline $\mathrm{HCW}$ & healthcare worker \\
\hline $\lg$ & immunoglobulin \\
\hline $\lg G$ & immunoglobulin G \\
\hline $\lg M$ & immunoglobulin M \\
\hline IHR & International Health Regulations \\
\hline IPC & infection prevention and control \\
\hline IU & international unit \\
\hline $\mathrm{mlU}$ & milli-international units \\
\hline MMR & measles, mumps and rubella \\
\hline MMRV & measles, mumps, rubella and varicella \\
\hline MREWG & Measles and Rubella Elimination Working Group \\
\hline $\mathrm{NACl}$ & National Advisory Committee on Immunization \\
\hline NML & National Microbiology Laboratory \\
\hline $\mathrm{P} / \mathrm{T}$ & Province/Territory \\
\hline PAHO & Pan American Health Organization \\
\hline PCR & polymerase chain reaction \\
\hline PHAC & Public Health Agency of Canada (the Agency) \\
\hline PHNC & Public Health Network Council \\
\hline PRNT & plaque reduction neutralization test \\
\hline RT-PCR & reverse transcriptase polymerase chain reaction \\
\hline SSPE & sub-acute sclerosing panencephalitis \\
\hline TDG & transportation of dangerous goods. \\
\hline VTM & viral transport media/medium \\
\hline WHO & World Health Organization \\
\hline
\end{tabular}




\section{DEFINITIONS}

\section{CONTACT}

A contact is defined as any individual who has:

- spent any length of time in a room or enclosed space with a confirmed measles case during that case's infectious period (i.e. approximately 4 days before rash onset to 4 days after rash onset); or

- spent time in a room previously occupied by a measles case, during that case's infectious period, within 2 hours after that individual left the room/space.

\section{ENDEMIC CASE}

In Canada, endemic measles refers to the situation in which a chain of transmission continues uninterrupted for a period greater than 12 months.

\section{EPIDEMIOLOGICAL LINKAGE}

A case has an epidemiological linkage if one or more of the following criteria are met:

- Contact with a confirmed measles case.

- Travel during the 21 days prior to onset of rash to a geographic area where measles is endemic or an outbreak of measles is occurring.

- Belonging to a defined risk group during an outbreak.

\section{HEALTHCARE SETTING}

For the purpose of this document, healthcare settings include any facility or location where healthcare is provided and include emergency care, pre-hospital care, acute care, long-term care, chronic/complex care, home care, ambulatory care and other facilities or locations in the community where care is provided (e.g., infirmaries in schools and residential facilities, etc (1).

\section{HEALTHCARE WORKER (HCW)}

Healthcare workers include individuals who provide health care or support services such as nurses, physicians, dentists, nurse practitioners, paramedics and sometimes emergency first responders, allied health professionals, unregulated healthcare providers, clinical instructors, students, volunteers and housekeeping staff (1).

\section{IMPORTED CASE}

A confirmed case, which, as supported by epidemiological and virological evidence, was exposed to the measles virus outside of Canada during the 7 to 18 days before onset of fever, or 7 to 21 days before onset of generalized rash.

\section{IMPORT-RELATED CASE}

A locally acquired infection occurring as part of a chain of transmission originated by an imported case, as supported by epidemiological or virological evidence, or both.

\section{MEASLES OUTBREAK}

As measles is eliminated in Canada, a single case would be considered unusual or unexpected. However, while measles activity remains high in other WHO regions, importations are expected to continue. The following is a working definition of a measles outbreak:

" Two or more confirmed cases linked, either epidemiologically or virologically or both.

\section{MULTI-JURISDICTIONAL OUTBREAK}

A multi-jurisdictional measles outbreak refers to an outbreak in which the infection is spread over more than one geographic jurisdiction (multiple P/Ts or countries) and/or management of an outbreak involves multiple agencies.

\section{PATIENT}

May apply to inpatients, outpatients, residents in long-term care/chronic care facilities, etc., and clients receiving care in the home and community settings. 


\section{SUSCEPTIBLE INDIVIDUAL}

An individual considered susceptible to measles meets the following criteria:

- lack of documented evidence of vaccination (one dose for adults 18 years of age and older, born in 1970 or later; two doses for children 12 months to 17 years of age) after the first birthday and given at least 4 weeks apart for MMR vaccine, or 6 weeks apart for MMRV vaccine;

- lack of laboratory evidence of prior measles infection; and

- lack of laboratory evidence of immunity (i.e. "reactive" or "positive" anti-measles lgG antibody or a previous measles antibody level of $\geq 200 \mathrm{mlU}$ per $\mathrm{ml}$ ) (2).

\section{UNKNOWN SOURCE CASE}

A confirmed case for which the source of infection was not identified.

\section{CONCLUSION OF AN OUTBREAK}

The conclusion of an outbreak should be at least 32 days ${ }^{1}$ following the rash onset date of the last outbreakassociated case, in order to account for delays in case reporting, subclinical and/or undiagnosed cases. 


\section{EXECUTIVE SUMMARY}

Measles in Canada: Canada has been free of endemic measles since 1998. However, cases due to importation will continue to occur as long as individuals travel between Canada and countries with disease activity. Maintaining elimination status will require enhanced surveillance activities, identifying and improving immunization coverage in susceptible populations, and providing education, both to the public and to health professionals, on the importance of immunization.

Guidelines History: In 1991, the Advisory Committee on Epidemiology (ACE) issued the "Guidelines for Measles Control in Canada". These guidelines presented a concerted approach to control, based on high levels of immunization, national surveillance with a standard case definition and focused action on outbreaks. However, this approach was critiqued as resource intensive with questionable success. Subsequently, as recommended by ACE, a Consensus Conference on Measles occurred in late 1992, with proceedings published in early 1993. In 1995, ACE published the "Guidelines for Control of Measles Outbreaks in Canada", a revision based on recommendations from the Consensus Conference.

Updated Guidelines: In support of the PAHO campaign to eliminate measles and rubella in the Americas, and in response to the prolonged outbreak of measles in Quebec in 2011, the 1995 Guidelines for Control of Measles Outbreaks in Canada have been updated.

The revision of the Guidelines was undertaken by the Measles and Rubella Elimination Working Group (MREWG), facilitated and supported by the Public Health Agency of Canada (the Agency). The MREWG working group is composed of a range of subject matter experts, with affiliations at the local, provincial, territorial and federal level.
The updated Guidelines have been prepared to assist Canadian public health authorities in their investigation and management of measles outbreaks, in order to: (i) prevent complications as a result of measles infection and (ii) limit secondary spread of measles during an outbreak.

Key changes and updates in the Guidelines for the Prevention and Control of Measles Outbreaks in Canada (2012) include:

- Updated immunization information to reflect current National Advisory Committee (NACl) on Immunization recommendations;

- Changes to susceptibility criteria for health care workers based on the updated Canadian Immunization Guide (CIG) (available online);

- Recommendation for jurisdictions to publish an outbreak summary within one year of the conclusion of an outbreak;

- Laboratory recommendations for clinical diagnosis and serology; and

- Assessment tools (algorithms) for healthcare settings. 


\section{INTRODUCTION}

\subsection{BACKGROUND}

Measles is a highly contagious, serious respiratory viral disease characterized by fever, and maculopapular erythematous rash. Symptoms include fever, cough, coryza, conjunctivitis and generalized maculopapular erythematous rash. Measles infection can result in serious complications such as blindness, encephalitis, or severe respiratory infections such as pneumonia.

Before widespread vaccination in 1980, measles was responsible for an estimated 2.6 million deaths worldwide each year. Despite the availability of a safe and effective vaccine, measles remains one of the leading causes of death among young children around the world, according to the World Health Organization (WHO).

In 1994 the Region of the Americas established the goal of measles elimination by 2000. The Pan American Health Organization (PAHO) defines elimination as: the lack of a circulating endemic genotype for at least one year and maintenance of $95 \%$ coverage of one dose of measles-containing vaccine, with an opportunity for a second dose.

Canada has been free of endemic measles since 1998. In Canada, publicly funded immunization programs have resulted in high coverage and, subsequently, low measles incidence rates. Both passive and active surveillance have been in place in Canada for years, allowing for prompt intervention when and where cases are identified. Cases will continue to occur in Canada as long as individuals travel out of and to Canada from countries with disease activity and there continue to be susceptible individuals and communities who are either unimmunized or underimmunized. Maintaining elimination of this disease will require enhanced surveillance activities, identifying and improving immunization coverage in susceptible populations, and providing education, both to the public and to health professionals, on the importance of immunization.
In support of the PAHO campaign to eliminate measles and rubella in the Americas, and in response to the prolonged outbreak of measles in Quebec in 2011; the 1995 Guidelines for Control of Measles Outbreaks in Canada have been updated. The guidelines have been revised to assist public health officials and clinicians in the management of measles cases and their contacts during outbreaks, and to limit the potential for measles to re-establish itself as an endemic disease in Canada.

\subsubsection{OBJECTIVES}

These guidelines were prepared primarily to assist Canadian public health authorities in their investigation and management of measles outbreaks, in order to:

- Prevent complications as a result of measles infection

- Limit secondary spread of measles during an outbreak

Public health authorities may need to adapt the guidelines and key recommendations to accommodate their local public health protocols and response. 


\section{EPIDEMIOLOGY OF MEASLES IN CANADA}

\subsection{PRE-ELIMINATION}

In Canada, the annual number of measles cases, as well as the annual incidence rate of reported cases have decreased dramatically since the disease became nationally notifiable in 1924 (Figure 1). From 1924 to 1958, an average of over 45,000 cases (range: $13,471-83,127$ ) were reported annually. A decrease was seen in the 1970s, with an average of 9,863 cases (range: 934-25,137) reported annually between 1969 and 1983. After the introduction of routine publicly-funded immunization programs for one-year-olds with a combined one-dose Measles Mumps and Rubella (MMR) vaccine in 1983, the average annual number of measles cases declined to 4,096 cases (range: 187-14,941). In 1996/1997, two-dose MMR vaccine schedules were introduced across Canada at 18 months or school entry, in conjunction with catch-up campaigns in several provinces, which led to further decreases in the number and incidence rate of measles reported in Canada.

FIGURE 1: Reported number of cases and incidence rates of measles in Canada, 1924 to 2011

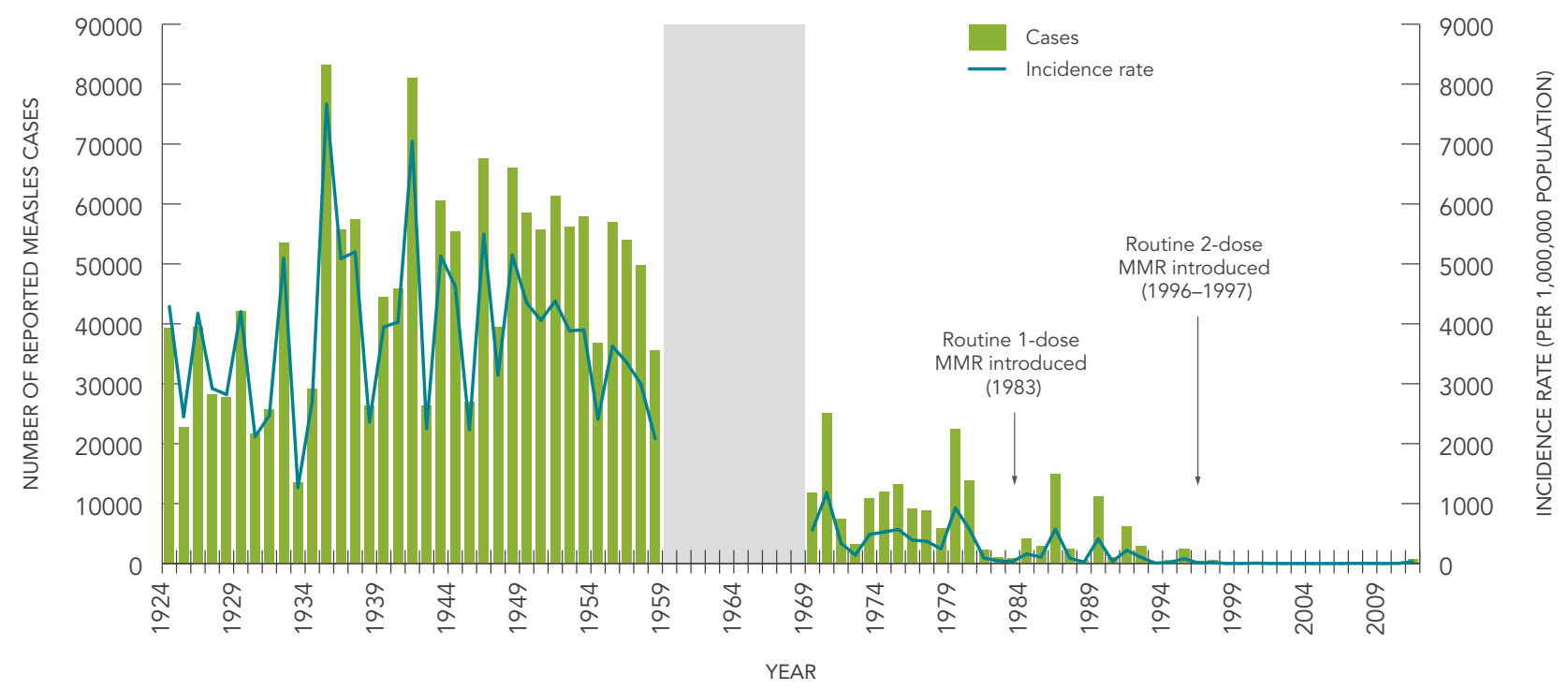

NOTE: measles was not nationally notifiable between 1959 and 1968. 
FIGURE 2: Reported number of cases and incidence rates of measles in Canada, 1998 to 2011

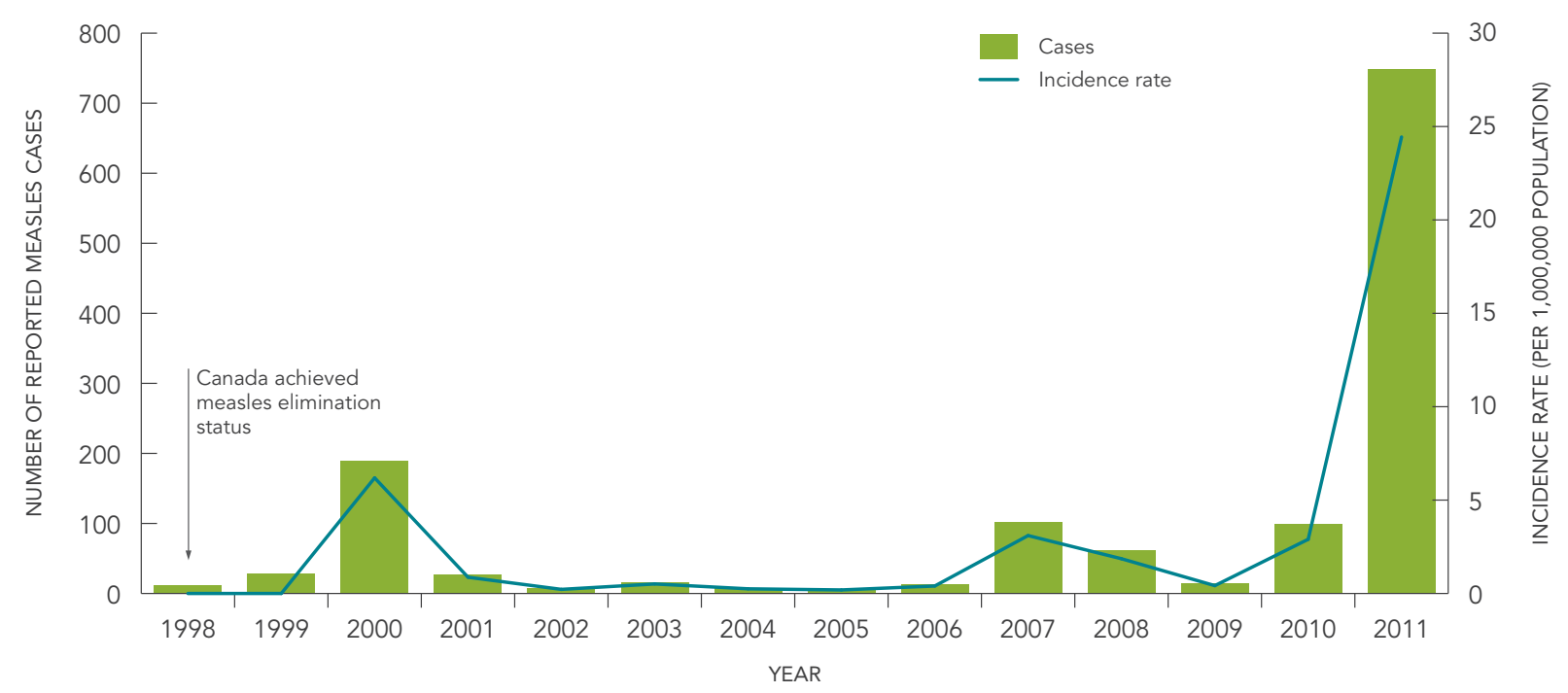

\subsection{POST-ELIMINATION}

The interruption of endemic measles transmission in Canada occurred in 1998. Cases reported since that time have been the result of importation from other countries (Figure 2). From 1998 to 2005, an average of 37 cases (range: 6-190, median=14) were reported annually. The average is skewed due to a large outbreak that occurred in the province of Alberta in 2000, in which a total of 123 cases were reported. Between 2006 and 2010, the average number of measles cases reported increased to 58 cases (range: 13-102, median=62). This increase can be attributed to outbreaks that occurred in 2007, 2008, and 2010. The province of Quebec experienced an epidemic of measles in 2011, with a total of 725 confirmed cases reported for that year.

\subsection{MEASLES OUTBREAKS IN CANADA}

There have been several measles outbreaks in Canada since the virus was eliminated. Outbreaks with greater than 10 cases that have occurred in the last five years are highlighted in Table 1. Four of these are briefly summarized below.

TABLE 1: Measles Outbreaks in Canada, by province, 2007 to 2011

\begin{tabular}{l|l|l|l|l}
\hline PROVINCE & YEAR & NUMBER OF CASES & DURATION (WEEKS) & STRAIN \\
\hline Quebec & 2007 & 94 & 24 & D4 \\
\hline Ontario & 2008 & 53 & 11 & D8 \\
\hline British Columbia & 2010 & 82 & 7 & D $8^{2}$ and H1 \\
\hline Quebec $^{3}$ & 2011 & 20 & 11 & D4 \\
\hline Quebec $^{4}$ & 2011 & 678 & 33 & D4 \\
\hline
\end{tabular}

2 There were two unique D8 strains circulating during this outbreak.

3 Outbreak commenced February 2011.

${ }^{4}$ Outbreak commenced April 2011. This total includes one outbreak-associated case reported in New Brunswick. 
There was a measles outbreak in Quebec involving 94 cases, which occurred from April 19 to September 26, 2007. This was a community and school outbreak in a population inadequately immunized for their age. The viral strain responsible for this outbreak was D4 (3).

Ontario experienced a community outbreak of measles involving 53 cases from March 12 to May 22, 2008.

Those in birth cohorts 1970-1979 and 1996 and later were most heavily affected. While the source of the outbreak was not confirmed, information from the investigation suggests that the index case acquired the infection from an undiagnosed imported case at a popular tourist destination in Ontario. The viral strain responsible for this outbreak was D8.
A large outbreak occurred in British Columbia following the Olympic and Paralympic Games. A total of 78 confirmed cases occurred from March 9 to April 28, 2010. While the original source of the outbreak remains unknown, two different strains were identified in outbreakassociated cases ( $\mathrm{H} 1$ and a D8). It is suspected that this outbreak was the result of spread from at least two unidentified index cases.

In 2011, Canada experienced the highest number of reported measles cases since 1995, and has had the largest measles outbreak in the Region of the Americas since the virus was eliminated in 2002. There were 752 confirmed cases of measles reported in Canada in 2011, with 678 (93.5\%) of these cases associated with a large outbreak in Quebec (Figure 3). This represents $56 \%$ of all measles cases reported in Canada since 1998.

FIGURE 3: Distribution of confirmed measles cases, by epidemiological week and province, Canada, 2011

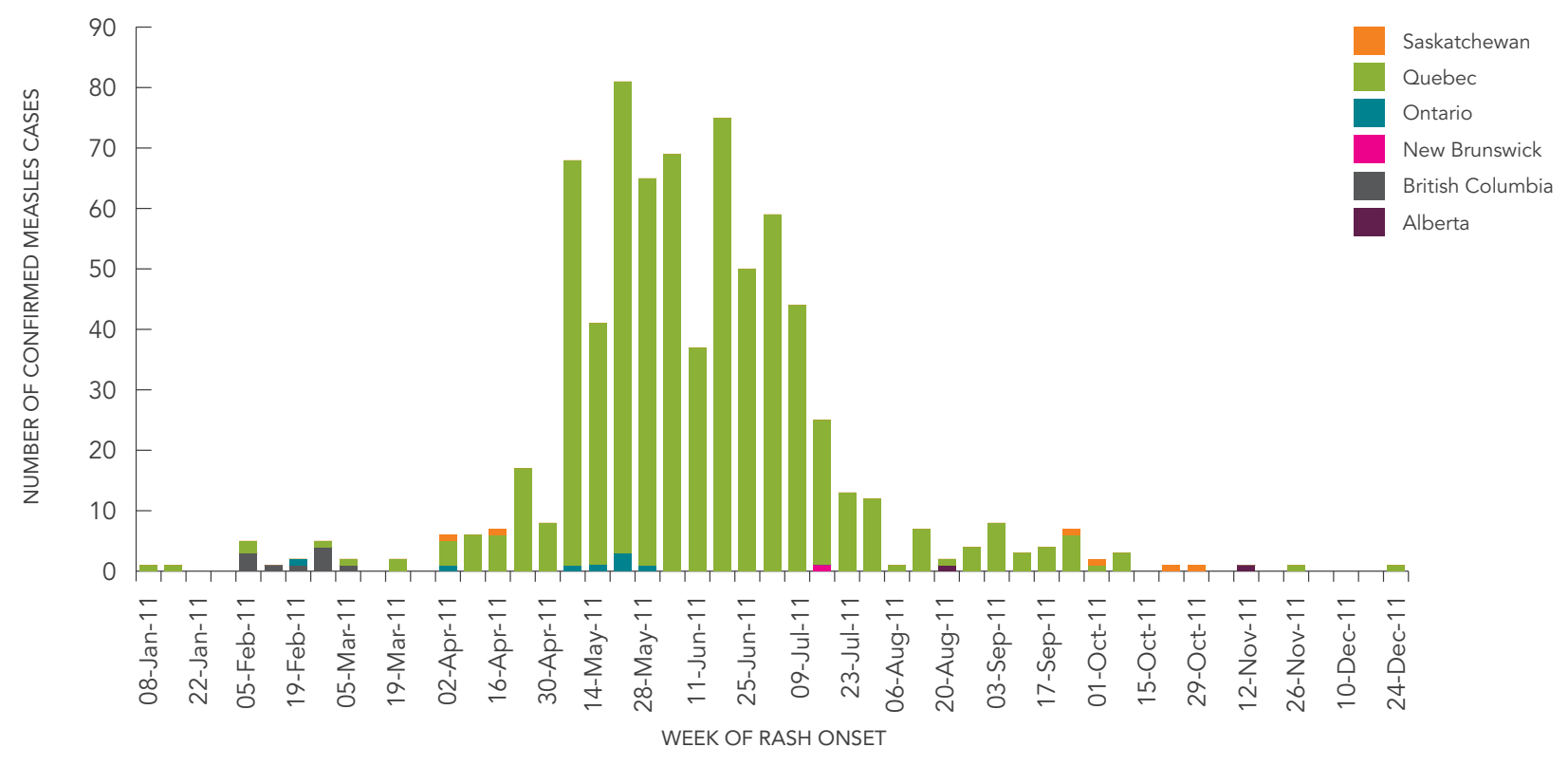

This outbreak occurred over 27 weeks, from April 7 to October 10, 2011. The index case of this outbreak was a school worker that had received one dose of measlescontaining vaccine, and who was likely exposed to measles virus at the international airport in Montréal. The outbreak began in the school, but eventually moved into the community. The increased transmission in schools is reflected in the age distribution of cases, with those aged $10-19$ years of age representing $66 \%$ of all cases.
The viral strain in the 2011 Quebec outbreak was characterized as genotype D4 and was the same as the D4 strain circulating in Europe in 2011 where more than 30,000 cases were reported. 


\section{SURVEILLANCE AND REPORTING}

In Canada, the reporting of notifiable diseases is mandated by provincial/territorial legislation and regulation, and reportable disease lists vary slightly by province and territory. Provincial and territorial reporting of notifiable diseases to the federal level is voluntary. While the Canadian Notifiable Disease Surveillance System (CNDSS) supports national, passive surveillance of more than 50 notifiable infectious diseases, the limited data collected as part of this system are insufficient for the surveillance of a disease under elimination, such as measles.

Following the national introduction of routine 2-dose immunization with MMR vaccine in 1996-1997, enhanced national confirmed-case surveillance of measles was implemented in 1998 to support timely case detection and response, to ensure the thorough epidemiological and laboratory investigation of measles cases, and to document progress towards the elimination of measles in Canada (4). Joint national surveillance of measles and rubella via the Canadian Measles and Rubella Surveillance System (CMRSS) commenced with the addition of rubella and congenital rubella syndrome/infection (CRS/I) to the national, enhanced surveillance system for measles in 2006 and 2007 respectively. The CMRSS continuously monitors the elimination of these diseases at the national level through the weekly solicitation of confirmed-case reports from all provinces and territories including zero reporting to the Agency. The Agency subsequently subsequently reports all nationally confirmed cases to PAHO on a weekly basis. All reported cases are reviewed to ensure they meet the national confirmed case definition prior to their addition to the national database. Surveillance data are used to support routine national and international reporting obligations, to identify gaps in national surveillance, and to inform national immunization strategies.
It is essential that reporting timelines be adhered to throughout the duration of the outbreak. Because the virus is eliminated in the Region of the Americas, increased activity is of significant interest to the $\mathrm{PAHO}$ and other countries in the Americas. Every effort should be made to ensure that reporting of confirmed cases continues on a weekly basis, as outlined in the CMRSS protocol. The Public Health Agency of Canada (PHAC) can provide support in the form of evidence, advice and human resources, should a request be made by the affected jurisdiction(s).

Measles cases that are confirmed as per the outbreak case definition should remain part of routine provincial/ territorial and national reporting of measles. 


\section{PUBLIC HEALTH MANAGEMENT}

\subsection{CASE MANAGEMENT}

\subsubsection{CASE IDENTIFICATION}

Investigate all confirmed, probable, and suspect cases of measles as soon as possible according to provincial and territorial guidelines (refer to Appendices B and C) and complete the individual case report for CMRSS (refer to Appendix D). The national case definition for measles was revised in 2009 and can be found at: www.phac-aspc.gc.ca/publicat/ccdr-rmtc/09vol35/ 35s2/index-eng.php (5). Although definitions for both confirmed and probable cases are provided, only confirmed cases are reported (PHAC).

\begin{tabular}{|c|c|c|}
\hline \multicolumn{2}{|l|}{ DEFINITION } & \multirow{3}{*}{$\begin{array}{l}\text { REPORTABLE TO PHAC } \\
\text { Yes } \\
\text { Report case through CMRSS }\end{array}$} \\
\hline \multirow[t]{7}{*}{ Confirmed Case } & Laboratory Confirmed & \\
\hline & $\begin{array}{l}\text { Laboratory confirmation of infection in the absence of recent } \\
\text { immunization with measles-containing vaccine: }\end{array}$ & \\
\hline & $\begin{array}{l}\text { - isolation of measles virus from an appropriate clinical specimen } \\
\text { OR }\end{array}$ & \\
\hline & $\begin{array}{l}\text { - detection of measles virus RNA } \\
\text { OR }\end{array}$ & \\
\hline & $\begin{array}{l}\text { - seroconversion or a significant (e.g. fourfold or greater) rise in } \\
\text { measles IgG titre by any standard serologic assay between acute } \\
\text { and convalescent sera } \\
\text { OR }\end{array}$ & \\
\hline & $\begin{array}{l}\text { - positive serologic test for measles lgM antibody using a } \\
\text { recommended assay in a person who is either epidemiologically } \\
\text { linked to a laboratory-confirmed case or has recently travelled to } \\
\text { an area of known measles activity }\end{array}$ & \\
\hline & $\begin{array}{l}\text { Confirmed by Epidemiological Link } \\
\text { - Clinical illness in a person with an epidemiologic link to a } \\
\text { laboratory-confirmed case }\end{array}$ & \\
\hline Probable Case & $\begin{array}{l}\text { Clinical illness } \\
\text { - in the absence of appropriate laboratory tests } \\
\text { OR } \\
\text { - in the absence of an epidemiologic link to a } \\
\text { laboratory-confirmed case } \\
\text { OR } \\
\text { - in a person who has recently travelled to an area of known } \\
\text { measles activity }\end{array}$ & No \\
\hline Clinical Case & $\begin{array}{l}\text { Clinical illness is characterized by all of the following features: } \\
\text { - fever of } 38.3^{\circ} \mathrm{C} \text { or greater } \\
\text { - cough, coryza or conjunctivitis } \\
\text { - generalized maculopapular rash for at least } 3 \text { days }\end{array}$ & No \\
\hline
\end{tabular}




\subsubsection{CASE INVESTIGATION}

Public health authorities should be notified of measles cases as soon as possible (refer to Appendices B and C). At present, a small fraction of the suspected and probable cases investigated are confirmed as measles. However, case investigation should not be delayed pending the return of laboratory results. All reports of suspected measles cases should be investigated as soon as possible.

It is important to collect information about the case and those who may have been exposed in order to determine the period of communicability and to offer the appropriate intervention. Essential components of case investigation include confirming the diagnosis, obtaining vaccination histories, identifying the sources of infection, and assessing the risk for transmission.

\subsubsection{DATA COLLECTION}

Epidemiological information should be collected to facilitate the completion of descriptive and analytical epidemiology by public health professionals. The following information should be collected during a measles episode or outbreak:

- demographic information

- clinical details including rash onset, complications and patient outcome

- laboratory details

- vaccination and travel history

- details of household and other contacts

- epidemiology information such as the potential transmission setting, source of exposure and occupation

Provincial/Territorial guidelines typically include information collection forms that can be used during case investigation. An enhanced measles case investigation form, similar to the one located in Appendix E, could be used to collect this information. Additional information may also be collected at the discretion of the Public Health Authority.

\subsubsection{MANAGEMENT OF CASES}

There is no specific treatment for measles; however, severe complications from measles can be avoided though supportive care that ensures good nutrition and adequate fluid intake (6). Public health advice to suspect, probable and confirmed cases would include the following: to practice good hand hygiene, avoid sharing drinking glasses or utensils and cover coughs and sneezes with a tissue or forearm. Provision of public advisories on when to seek care is at the discretion of the Public Health Authority.

\subsubsection{EXCLUSION OF CONFIRMED CASES}

Individuals diagnosed with measles should be advised to stay home (self-isolate from: child care facilities, schools, post-secondary educational institutions, work places, healthcare and other group settings; and away from non-household contacts) for four days after the appearance of the rash. This should apply whether the case had been previously vaccinated or not. Self-isolation will help to prevent transmission of the virus.

\subsection{CONTACT MANAGEMENT}

Within 24 hours of reporting a suspect case of measles, all contacts should be identified and classified as susceptible or non-susceptible (Refer to Definitions). The immunization status of community contacts of cases should be ascertained to determine susceptibility to measles.

Public Health Authorities should determine the extent of contact tracing to be completed during an outbreak, based on the outbreak context and the resources available. The following groups and individuals could be considered contacts during outbreaks:

1. Household contacts

2. In a daycare/education facility: all employees, volunteers, students, bus drivers, members of a sports team or club

3. In a workplace: Individuals who share the same schedule and/or office location as the case

4. In a health care facility: individuals who shared the same room, waiting room or exam room without appropriate protection 


\subsubsection{SUSCEPTIBLE CONTACTS}

Measles transmission is dependent on several factors including population vaccination coverage rates (9). Individuals without a history of natural immunity or not successfully immunized against measles are considered to be at increased risk of acquiring measles. Measles complications disproportionately affect persons suffering from malnutrition, immunodeficiency and pregnant women (10). Adults born prior to 1970 are at lower risk of measles infection because they are presumed to have natural immunity to measles (11). Additionally, children born to mothers with a naturally acquired immunity inherit immunity for longer periods of time than infants born to mothers with vaccine induced immunity (7). Canadians travelling to measles endemic areas, healthcare workers, military recruits and students attending post-secondary institutions are at higher risk of exposure to measles.

A high risk contact is one that is at an increased risk of measles complications (10). These contacts meet the criteria of a susceptible individual, but also fall into following groups:

- Pregnant

- Infants

- Immunocompromised

Although there has been no evidence of congenital syndrome resulting from maternal measles infection during the first trimester, measles infection during pregnancy can result in complications (12). A review conducted from 1988-1990 of twelve women hospitalized for measles while pregnant revealed complications of pneumonitis (58\%), hepatitis (58\%) and premature labor (33\%) (13). When measles infection occurs in late pregnancy, congenital infection is possible.

Immunocompromised persons have an increased susceptibility to infection, compared to immunocompetent persons. Deficiencies in the adaptive immune system may be present, which could result in decreased ability to clear the virus and increased severity and duration of infection (14). There is also an increased likelihood of nosocomial acquisition (15).

\subsubsection{EXCLUSION OF SUSCEPTIBLE CONTACTS}

Susceptible contacts that refuse or cannot receive MMR vaccine or immune globulin may be excluded from childcare facilities, schools, and post-secondary educational institutions at the discretion of the Medical Officer of Health; and may be required to self-isolate from work places, or other group settings, including travel. If exclusions occur, the period of exclusion should extend from 5 days after the first exposure and up to 21 days after the last exposure, or until the individual is:

- adequately immunized (having had documentation of at least one recent dose of a measles-containing vaccine), or

- demonstrates serological confirmation of immunity or

- Has received immunoglobulin, if eligible (Refer to section 4.2.3)

Consideration should be given to: the number of susceptibles in that setting; the presence of high risk individuals, susceptible infants, or immunocompromised individuals; and the reliability of the incubating individual to comply with early recognition and self-isolation.

In collaboration with public health authorities, it is recommended that schools/educational institutions have a mechanism in place to allow for prompt identification of susceptible students.

\subsubsection{VACCINES}

Vaccination of susceptible individuals represents an important risk mitigation strategy. High vaccine coverage is needed to sustain measles elimination (4). In Canada, a two-dose immunization schedule is recommended for the routine immunization of children (2). This recommended schedule infers high levels of individual immunity by reducing the likelihood of vaccination failure (7). A robust surveillance system allows for an assessment of vaccination impact in populations and early recognition of outbreaks.

Susceptible, immunocompetent individuals 12 months of age and older who are exposed to measles may be protected from measles disease if MMR vaccine is given within 72 hours of the exposure. MMR vaccine may be recommended for children between 6 months 
and 12 months of age for post-exposure management if it is given within 72 hours of exposure; however, two additional doses of measles-containing vaccine must be administered after the child is 12 months old (and at least 28 days from the previous dose) to ensure long lasting immunity to measles. There are currently no data on the use of MMRV for susceptible children or adults in postexposure or outbreak situations involving wild-type measles, mumps, rubella and varicella viruses; however, MMRV would not be required in outbreaks or exposures involving any single viral pathogen, where either MMR or univalent varicella vaccine may be utilized(8).

Measles vaccine (MMR, MMRV) is contraindicated in individuals with a previous anaphylactic reaction to a measles-containing vaccine. If there is a compelling reason to re-immunize an individual who has had a prior anaphylactic reaction to measles vaccine, MMR skin testing and graded challenge in an appropriately equipped facility can be considered. However, the possibility of a hypersensitivity reaction to the MMR skin test or during the graded challenge must be considered.

\subsubsection{IMMUNOGLOBULIN}

Prophylactic use of immunoglobulin $(\mathrm{lg})$ has been shown to be effective in modifying or preventing disease. Susceptible exposed individuals who present more than 3 days (72 hours) after exposure (when MMR vaccine no longer provides post-exposure protection) but less than 6 days after exposure (when Ig may still provide postexposure protection) can also be considered for lg. (8) . Ig should be considered for susceptible contacts of measles (see section 4.2.1), particularly immunocompromised people and pregnant women for whom measlescontaining vaccine is contraindicated and infants less than 6 months of age. Infants under 6 months of age are usually considered immune due to antibodies transferred in utero from the mother. If, however, the mother contracts measles or is known to be non-immune, the infant should get lg.

Measles antibody titre is known to decline more rapidly over time in HIV-infected as compared to HIV-uninfected children, therefore, a dose of Ig is recommended for prophylaxis in HIV-infected children after a known exposure to confirmed measles, even with documented previous MMR immunization.
GamaSTAN® S/D (immune globulin [human]), Grifols Therapeutics Inc. (manufacturer), Grifols Canada Ltd. (distributor), (lg) is a sterile, concentrated solution containing $15 \%$ to $18 \%$ immune globulin. The recommended dose of GamaSTAN $®$ S/D (lg) for healthy individuals exposed to measles is $0.25 \mathrm{~mL} / \mathrm{kg}$ body weight. The dose for exposed individuals who have underlying malignant disease or who are otherwise immunologically deficient is $0.5 \mathrm{~mL} / \mathrm{kg}$ body weight. A maximum dose of $15 \mathrm{~mL}$ should not be exceeded. GamaSTAN $®$ S/D should only be given by the intramuscular route. For complete prescribing information, consult the product leaflet or information contained within the authorized product monograph available through Health Canada's Drug Product Database at: http://webprod5.hc-sc.gc.ca/ dpd-bdpp/index-eng.jsp.

\subsection{GATHERINGS}

Gatherings apply to events of all sizes, in both private and public forums. Gatherings include social or religious functions, sports activities, shopping excursions, concerts, conferences and meetings, as well as public transit. During an outbreak, events need not be cancelled, although jurisdictions may consider postponing gatherings that may pose a risk for transmission or involve vulnerable populations (e.g., well-baby clinics).

It is prudent for organizers to use these opportunities to inform participants about the potential for disease transmission and methods to minimize the spread of the disease, including immunization, practising good hand hygiene, avoiding sharing drinking glasses or utensils, covering coughs and sneezes with a tissue or forearm, and staying home when ill. Should an outbreak of measles occur during a gathering event, public health authorities should communicate the exposure setting to the public.

\subsection{TRAVELLERS}

When a case of measles is being investigated, the travel history both within Canada and outside of Canada as a potential risk factor should be considered. The public health authority that identifies an infectious or potentially infectious traveller should notify the public health authority 
where the case resides and those of any known contacts, so that authorities may follow up accordingly. The notifying province/territory should also report the confirmed case to the Centre for Immunization and Respiratory Diseases (CIRID) at PHAC.

When cases or contacts are from another country, the identifying provincial/territorial public health authority should notify the Centre for Immunization and Respiratory Diseases (CIRID) at the Public Health Agency of Canada (the Agency), which will contact the appropriate authority of the affected country through Canada's National International Health Regulations (IHR) Focal Point. When international travellers associated with measles cases or contacts are identified by a Quarantine Officer at an international point of entry, the Office of Quarantine Services at the Agency will ensure the appropriate local, provincial/territorial or international public health authority is notified.

When multiple jurisdictions are involved it is not always clear who should report a case. Case reporting is important for describing and monitoring the epidemiology, impact and spread of an outbreak. Therefore, during outbreaks, the jurisdiction that initially identifies and primarily handles the case is asked to report it. This decision rule is flexible and should be evaluated for each case, considering place of residence, travel itinerary and the public health response or intervention that was implemented.

\subsubsection{AIR TRAVEL}

If a communicable disease, such as measles, is suspected onboard an airplane while in flight, airline crew are to follow procedures to notify the airport authority. The latter will notify a Quarantine Officer, who will meet the aircraft upon arrival. If measles is suspected, the Quarantine Officer will collect contact information from travellers seated in a two row radius around the suspect case. If measles is confirmed, the Quarantine Officer will ensure that public health authorities at the point of entry and in the jurisdiction where the case resides are notified and provided with contact information for the potentially exposed travellers.
If a case of measles has travelled by air during the infectious period (4 days before onset of symptoms to 4 days after the appearance of rash) public health authorities should be consulted. Contact tracing using a passenger manifest may be performed to inform other travellers of their potential exposure, although there is insufficient evidence to recommend this type of contract tracing in all cases in Canada. A great majority of Canadians are considered to be immune to measles, through either natural infection or immunization. Although there have been several instances in which measles cases were infectious during flights to Canada, these events have not resulted in documented in-flight measles transmission.

A risk-based approach including respiratory symptoms in the case and the duration of flight should be considered in deciding if the risk posed by the traveller is sufficiently high to justify contact-tracing.

The Office of Quarantine Services at the Agency can assist public health authorities in obtaining a flight manifest however it should be noted that flight manifests are not kept indefinitely and do not contain contact information on all travellers. If contact tracing is not feasible, a public advisory to notify the public of the potential exposure may be considered.

Communication of the traveller's itinerary should be considered by the overseeing public health authority so that other jurisdictions are aware of the potential exposure, as they may have different protocols or be assessing changes in their own measles activity. Non-nominal travel details should be shared with public health professionals across the country through the Public Health Alerts module of the Canadian Network for Public Health Intelligence (CNPHI) (www.cnphi-rcrsp.ca) a secure, web-based application. In Canada, airlines can refuse permission to board to individuals who appear to have an infectious disease.

\subsubsection{MARINE TRAVEL ON CRUISE SHIPS}

In the event of an identified measles outbreak onboard a cruise ship, the cruise ship's health services would have responsibility for the traveller's health during the cruise and would follow up with contacts according to the conveyance operator's policy. 
At least 24 hours prior to port arrival, ships are to report to Canadian port authorities as to the presence and status of anyone aboard who may be ill with a communicable disease, such as measles. The port authority will notify a Quarantine Officer, who will meet the ship upon arrival. If measles is confirmed, the Quarantine Officer will ensure that public health authorities at the point of entry and in the jurisdiction where the case resides are notified.

In the event that a case that was infectious while onboard a cruise ship is detected following travel, the conveyance operator may be able to assist in informing other passengers and crew of the potential exposure. A public advisory may also be considered.

In Canada, cruise lines can refuse permission to board to individuals who appear to have an infectious disease.

\subsubsection{OTHER TRAVEL MODALITIES}

Contact tracing for measles exposures on other conveyances such as buses, trains or ferries may be desirable however passenger manifests are rarely available for these conveyance types. In such cases, a risk-based approach including respiratory symptoms in the case and the duration of travel can be used to determine if a public advisory to warn other travellers of the potential exposure is warranted. 


\section{HEALTH CARE SETTINGS}

Community measles outbreaks can have considerable impact on healthcare delivery as a result of the highly infectious nature of measles and the potential for measles transmission in healthcare settings. The measles virus is amongst the most person-to-person transmissible of all microbial agents $(2,16)$. It can survive at least two hours in evaporated droplets and the airborne spread of these fine particles has been implicated in closed settings (17), including healthcare settings (18-28). Transmission in healthcare settings can even occur when index cases are no longer present $(20,21)$ as a result of the persistence of the virus in the air or on environmental surfaces. During community outbreaks, health care workers (HCWs) may be exposed to measles not only in the community but also in healthcare settings.

For the prevention of measles transmission in the healthcare setting, emphasis should be placed on the pre-employment assessment of immunity to measles and in providing two-doses of measles, mumps and rubella (MMR) vaccine to $\mathrm{HCWs}$ where indicated, before an outbreak occurs $(2,16,29)$. Immunity to measles should be considered a condition of employment for new HCWs $(1,10,29)$. These two strategies will result in minimal disruption to healthcare delivery during community measles outbreaks.

The National Advisory Committee on Immunization (NACl) addresses the immunization of HCWs in the most recent version of the Canadian Immunization Guide (CIG) (8). $\mathrm{HCWs}$, regardless of their year of birth, who do not have documented evidence of receiving two doses of measles-containing vaccine on or after their first birthday, or laboratory evidence of immunity, or a history of laboratory confirmed measles disease should be vaccinated accordingly so that they have received two doses of MMR vaccine, unless a contraindication to measles vaccination is present (i.e. history of anaphylaxis after previous administration of the product, proven immediate or anaphylactic hypersensitivity to any component of the product (with the exception of egg allergy) or its container, pregnancy, or pre-existing immunodeficiency ). HCWs that have received only one dose of vaccine and have not demonstrated immunity to measles should be given one additional dose. A positive IgG result indicates immunity.
In addition to the recommendations for the management of measles in healthcare settings (Refer to Appendix F), algorithms to assist with assessing $\mathrm{HCWs}^{\prime}$ susceptibility to measles (Algorithm A), managing $\mathrm{HCWs}$ who are close contacts of a case of measles (Algorithm B), and managing patients who are close contacts of a case of measles (Algorithm C) are provided in Appendix G.

\subsection{INFECTION PREVENTION AND CONTROL MEASURES FOR SUSPECTED OR CONFIRMED MEASLES}

Healthcare settings should be notified when measles cases are present in the community and provided with information on clinical recognition and laboratory diagnosis of suspected cases. Emergency departments and ambulatory care settings should be advised to triage suspected patients as expeditiously as possible into an airborne infection isolation room (AIIR) to avoid exposure to contacts in waiting rooms. Outpatient clinics and home care organizations should have a system in place to identify patients with suspected or confirmed measles. Outpatient clinic appointments for suspected or confirmed measles patients should be postponed unless medically necessary, and until there is access to an AIIR and precautions are in place until placement in the AIIR. Home care patients with suspected or confirmed measles should be cared for only by measles immune HCWs.

Inpatients suspected or confirmed to have measles should be cared for in an AIIR from the onset of symptoms (fever, maculopapular rash, and cough/coryza/ conjunctivitis) up to and including four days after onset of maculopapular rash $(1,10,16,29)$. If an AIIR is not available (e.g., in long-term care facilities, etc.) the patient should be placed in a single room away from susceptible patients until transfer to a facility with an AIIR can be arranged (1).

Immunocompromised patients may have prolonged excretion of the virus from their respiratory tract and be contagious for the duration of their illness. They are likely to require a longer duration of additional precautions (16). 
The role of virologic studies in identifying when immunocompromised patients can be safely taken off precautions has not been defined. The conservative approach is maintaining patients on precautions until all their measles symptoms have resolved.

Susceptible HCWs should not enter the room of a patient with suspected or confirmed measles or the room of a patient who is in the infectious period. In circumstances when this is unavoidable, the HCW should wear a respirator. Immune HCWs do not require additional precautions (i.e., respirators) to enter the AIIR of an individual with suspected or confirmed measles $(1,29)$.

Specifications for appropriate functioning and monitoring of AllRs should be established and maintained (30,31).

\subsubsection{MANAGEMENT OF HEALTHCARE WORKERS EXPOSED TO CASES}

Management of exposed HCWs should be carried out in consultation with occupational health and local public health authorities.

HCWs that have been exposed to a confirmed case of measles should have their immune status reviewed (29). If HCWs have had two documented doses of measlescontaining vaccine or documentation of antibodies to measles, they can be considered immune $(8,29)$ and can return to work. If HCWs have had only one documented dose of measles-containing vaccine, without laboratory evidence of immunity or history of laboratory confirmed measles, it is recommended that they be tested for measles IgG antibody and one dose of MMR vaccine be administered immediately. While waiting for the serology results, HCWs should be excluded from work from the fifth day to the $21^{\text {st }}$ day after the last exposure $(1,10,16)$. If their IgG measles antibody results are positive, they can be considered immune and return to work. If their lgG measles antibody results are negative, they should be considered susceptible. Susceptible HCWs should be given a second dose of MMR vaccine 28 days after the first dose, and exclusion from work should continue from the fifth day to the $21^{\text {st }}$ day after the last exposure regardless of whether they received the vaccine or immune globulin after the exposure $(1,10,16)$.

\subsubsection{MANAGEMENT OF PATIENTS EXPOSED TO CASES}

Management of patients who have been exposed to measles should be carried out by the healthcare organization's infection control (IPC) professionals or delegate in consultation with local public health authorities.

Patients who have been exposed to a confirmed case of measles should have their immune status reviewed $(1,8)$. Patients who are adults aged 18 years of age and older with one dose, children 12 months to 17 years of age with two doses, were born before 1970 or have had two documented doses of measles-containing vaccine or documentation of antibodies to measles can be considered immune $(1,8)$. If patients have had one documented dose of measles-containing vaccine or no laboratory evidence of immunity or a history of laboratory confirmed measles, it is recommended that they be tested for measles IgG antibody and one dose of MMR vaccine be administered immediately. While waiting for the serology results, patients should be isolated in an AIIR from the fifth day to the $21^{\text {st }}$ day after the last exposure (1). If their lgG measles antibody results are positive, they can be considered immune and placed into a regular room. If their lgG measles antibody results are negative, they should be considered susceptible. Susceptible patients should be given a second dose of MMR vaccine 28 days after the first dose, and be isolated in an AIIR from the fifth day to the $21^{\text {st }}$ day after the last exposure regardless of whether they received the vaccine or immune globulin after the exposure (1). 


\section{LABORATORY GUIDELINES FOR THE DIAGNOSIS OF MEASLES}

\subsection{GUIDELINES FOR LABORATORY TESTING}

Diagnosis of measles requires careful evaluation of clinical, laboratory and epidemiological data and on occasion it can be challenging. As endemic transmission has been interrupted in the region of the Americas, the incidence of measles is low and sporadic cases that occur following travel should be carefully investigated.

The very low incidence of measles in elimination settings results in a corresponding decrease in the positive predictive value of serological testing, complicating the interpretation of positive IgM serology results for suspected cases which lack an epidemiological link to a confirmed-case (32). In a highly vaccinated population, cases may occur in previously immunized individuals, for whom serology may provide contradictory results.
Molecular detection of the virus is therefore preferred to confirm the diagnosis of suspected cases. Timely acquisition of appropriate specimens in every suspected measles case is of essential importance. Correct diagnosis is very important not only for proper patient and contact care, but also for monitoring the efforts of measles eradication in the region of the Americas.

This section is based on recent experiences in measles diagnostics around the world and follows the principles of the guidelines of the WHO Measles and Rubella Laboratory Network (33) (available at www.who.int/ immunization_monitoring/laboratory_measles_resources/ en/index.html).

A comprehensive description of measles diagnostics can be found in the Manual of Clinical Microbiology $(34,35)$, while more technical details on the tests can be found in Table 2. More detailed laboratory guidelines for the diagnosis of measles can be found in Appendix $\mathrm{H}$.

TABLE 2: Summary of laboratory diagnostics for measles 


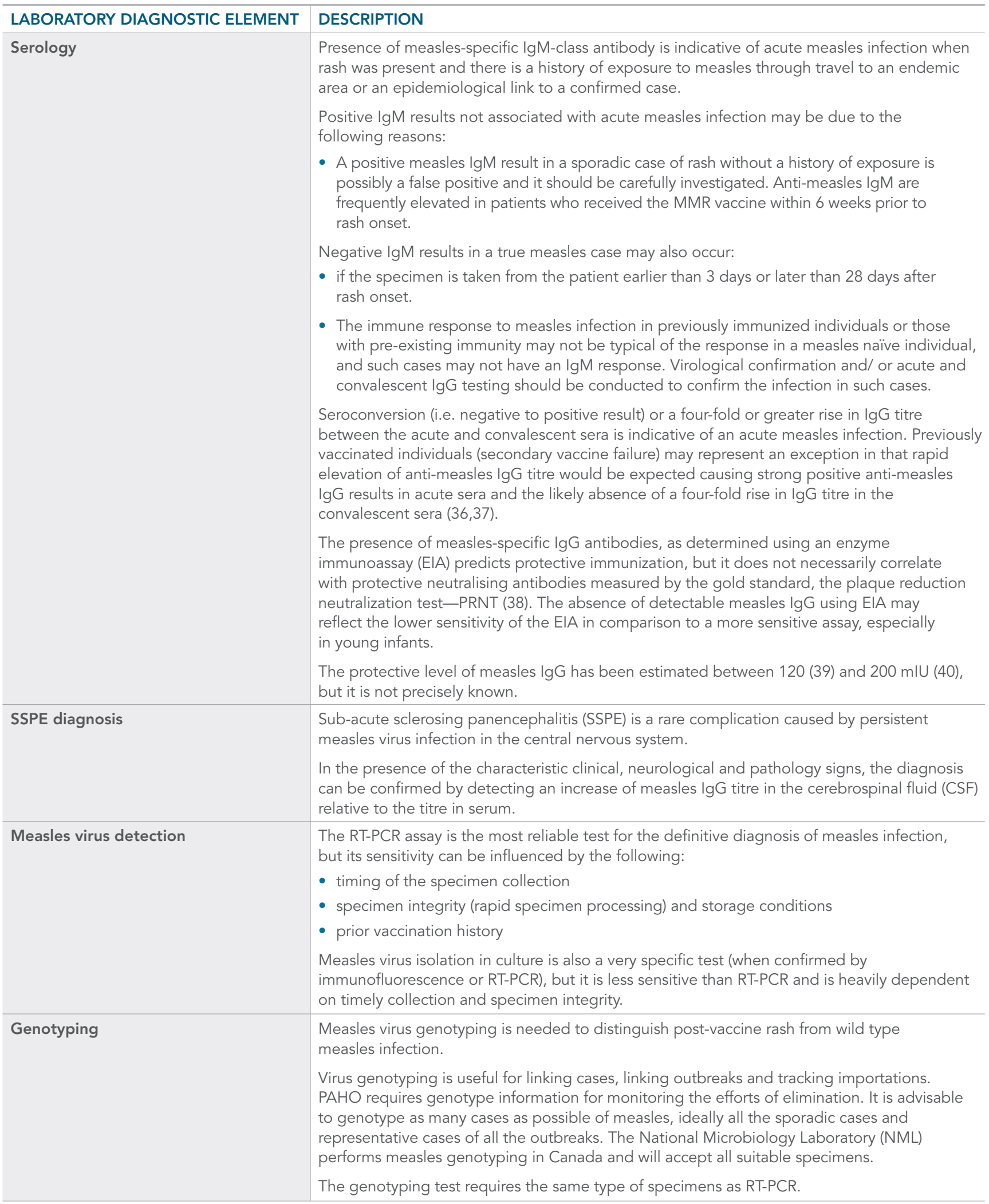




\begin{tabular}{l|l}
\hline LABORATORY DIAGNOSTIC ELEMENT & DESCRIPTION \\
\hline Interpretation of laboratory results & $\begin{array}{l}\text { In order to properly interpret laboratory results and to assess the performance of measles } \\
\text { diagnostic assays, both clinical and epidemiologic information need to be considered along } \\
\text { with the laboratory information (e.g. prior vaccination history, travel history, timing of sample } \\
\text { collection relative to onset of symptoms). Therefore, communication and information sharing } \\
\text { between public health and the laboratory are essential. }\end{array}$ \\
& $\begin{array}{l}\text { A positive RT-PCR result or positive lgM result in a patients with rash and with history of travel } \\
\text { in a measles endemic area or with an epidemiological link to a confirmed case, are diagnostic } \\
\text { for measles infection. }\end{array}$ \\
& $\begin{array}{l}\text { Seroconversion or a fourfold increase of measles IgG in a patient with rash and no history of } \\
\text { recent MMR vaccination is also diagnostic for measles. }\end{array}$ \\
& $\begin{array}{l}\text { Negative results by RT-PCR and negative IgM-class antibody detection may not be sufficient } \\
\text { to rule out measles infection in some cases, particularly if the specimen for PCR was collected } \\
\text { later than } 7 \text { days after symptom onset. } \\
\text { Serological results for previously vaccinated individuals (secondary vaccine failure) will likely } \\
\text { not follow the paradigm associated with acute primary measles in unvaccinated individuals. } \\
\text { Anti-measles IgM antibody response may be weak or not detectable, and a rapid elevation } \\
\text { of anti-measles IgG titre would be expected causing strong positive anti-measles IgG results } \\
\text { in acute sera and the likely absence of a four-fold rise in IgG titre in the convalescent sera } \\
\text { (36,37). In these individuals, the timely collection of specimens for measles virus detection } \\
\text { (RT-PCR) is recommended. }\end{array}$ \\
\hline
\end{tabular}

\subsection{ROLES AND RESPONSIBILITIES}

Provinces and territories normally have the responsibility of front-line diagnostics of suspected measles cases.

Provincial or territorial Public Health should have a method in place for informing and updating physicians and local health authorities regarding the issues surrounding measles laboratory investigation, particularly regarding the appropriate collection and handling of specimens. The public health authorities should also ensure that there is a procedure in place to collect relevant patient and clinical information that must accompany the specimens, and that the specimens transported to the testing laboratory safely and efficiently.
Provincial and territorial laboratories should ensure that health professionals are aware of the appropriate timing, storage and transport of the specimens for measles diagnostics. Provincial and territorial laboratories normally perform serological testing for measles IgM and IgG and they should ensure that the results are reported with a turnaround time of no more than 72 hours. They should ensure that their testing methods are accredited and participate in regular proficiency programs. "Red rash" screening for rubella and parvovirus B19 should also be available. Provincial and territorial laboratories have a mechanism in place to send specimens for molecular testing (if not done on site) and genotyping to the NML.

The National Microbiology Laboratory (NML) is a WHO Regional Reference Laboratory for measles and rubella and provides genotyping ideally for all cases of measles in Canada. Measles sequences are reported to $\mathrm{PAHO}$ and WHO measles databases. The NML also provides regular measles serology and molecular proficiency testing panels to provincial and territorial laboratories. The NML assists provincial and territorial laboratories for test evaluation, troubleshooting and speciality testing, like SSPE serology. 


\section{IMMUNIZATION}

\subsection{NACI RECOMMENDATIONS ON THE USE OF THE MEASLES VACCINE}

In Canada, immunization is a shared responsibility among the federal/provincial/territorial (F/P/T) governments. Approval of vaccine products and recommendations on the use of vaccines are made by the federal government. Provinces and territories are responsible for planning, funding and delivering immunization programs in their jurisdiction.

Recommendations on the use of specific vaccines are made by the National Advisory Committee on Immunization (NACl). $\mathrm{NACl}$ is an advisory group of immunization experts from across Canada which provides the Agency with ongoing and timely medical, scientific and public health advice on vaccines authorized for sale in Canada. NACl publishes detailed recommendations pertaining to the use of vaccines in Canada. These recommendations are contained in the CIG and are available at www.phac-aspc.gc.ca/publicat/cig-gci. The current $\mathrm{NACl}$ recommendations for the use of the measles vaccine are as follows:

\section{CHILDREN (YOUNGER THAN 18 YEARS OF AGE)}

Two doses of measles-containing vaccine should be given for routine immunization of children and for immunization of children and adolescents who have missed measles immunization on the routine schedule. MMRV vaccine may be used in healthy children aged 12 months to 12 years. The minimum intervals between doses for unimmunized children or adolescents who are catching up with their immunizations are 4 weeks for MMR vaccine and 6 weeks for MMRV vaccine.

$\mathrm{NACl}$ recommends that the first dose of MMRV vaccine be administered at 12 to 15 months of age, and the second at 18 months of age or any time thereafter, typically before school entry. As stipulated in the product monograph, the doses may be administered more closely together, with a minimum interval of six weeks between doses.
Two doses of MMRV vaccine a minimum of six weeks apart may also be administered up to 12 years of age as catch-up for those not previously immunized with MMR and varicella vaccines and who are susceptible to these vaccine-preventable diseases.

People under 12 years of age who have had only one dose of a varicella-containing vaccine should be offered a second dose as a catch-up unless they have had confirmed varicella disease. If the child has already received two doses of MMR vaccine, then the second varicella dose should be provided as a univalent varicella preparation. If the child has received only one dose of MMR vaccine and one dose of varicella vaccine, then the second dose can be provided as MMRV or as MMR and varicella separately. Refer to Tables 2 and 3 of Part 4: Active Vaccines-Varicella (Chickenpox) Vaccine in the CIG for specific timelines regarding catch-up vaccination.

\section{ADULTS (18 YEARS OF AGE AND OLDER)}

Routine immunization: Adults without contraindications, born in 1970 or later who do not have documented evidence of receiving measles-containing vaccine on or after their first birthday, or laboratory evidence of immunity, or a history of laboratory confirmed measles infection should be immunized with one dose of MMR vaccine. Immunity to measles, mumps and rubella should be reviewed in all women of reproductive age and vaccination should be recommended to all non-pregnant women. Women should delay pregnancy by 4 weeks following vaccination with MMR vaccine.

Adults born before 1970 are presumed to have acquired natural immunity to measles and do not need vaccine except for those identified at risk. 


\subsection{IMMUNIZATION PROGRAMS IN CANADA}

Measles immunization programs began in Canadian provinces and territories in 1967 with a live measles vaccine. By 1983, all provinces and territories across Canada had implemented routine measles-mumps-rubella combined vaccine at 12 months. $\mathrm{NACl}$ recommendations for a two-dose schedule of the MMR vaccine were published in 1996. Over 1996 and 1997, all provinces and territories introduced either a routine second dose of MMR vaccine or a measles-rubella combined vaccine given at 18 months of age or four to six years of age (at school entry) to their publicly-funded immunization programs. Currently, nine out of thirteen jurisdictions administer the second dose of measles, mumps and rubella-containing vaccine (MMR/MMRV) at 18 months of age, while the remainder of the jurisdictions administer the second dose of the measles mumps and rubella-containing vaccine between four and six years of age.

At the same time or following implementation of the second dose of measles-containing vaccine, many jurisdictions also implemented second dose catch-up immunization programs or campaigns for older cohorts. While national recommendations for the use of specific vaccines are made by the $\mathrm{NACl}$, policy related to immunization programs and is set at the jurisdiction level by provinces and territories that determine immunization schedules in their jurisdiction based in part on $\mathrm{NACl}$ recommendations as well as other factors. As a result, immunization programs are not fully harmonized between provinces and territories such that jurisdictions differ in the timing at which certain vaccines are offered through publicly-funded programs. The most recent routine immunization schedule of vaccines offered to infants and children by provinces and territories may be accessed at: www.phac-aspc.gc.ca/im/ptimprogprogimpt/table-1-eng.php.

\subsection{VACCINE SUPPLY}

The status of MMR and MMRV (measles, mumps, rubella and varicella) vaccine supply should be considered before undertaking immunization initiatives as part of the outbreak response. As with any new immunization initiative, vaccine supply should be coordinated in consultation with F/P/T counterparts through the Vaccine Supply Working Group (VSWG) and the Canadian Immunization Committee (CIC). While MMR vaccine supply has been stable in recent years, factors such as introduction of mumps-containing immunization catch-up programs in some jurisdictions, measles immunization programs, and the broader use of MMRV vaccine could all affect the availability of MMR vaccine.

In the event of an actual or projected shortage of MMR vaccine during an outbreak, the identification of priority groups may be necessary. In the United Kingdom, the following priority order was considered: routine immunization for infants and children, immunization of rubella-susceptible women of child-bearing age, and immunization of susceptible (measles, mumps or rubella) HCWs, followed by immunization of other susceptible individuals as defined by the epidemiology of the outbreak. Prioritization should take place in consultation with the $\mathrm{ClC}$ and the Vaccine Supply Working Group.

\subsubsection{MEASLES-CONTAINING VACCINE IN CANADA}

There are currently three measles-containing vaccines used in Canada. The measles vaccine is only available in combination with the mumps and rubella vaccine or with the mumps, rubella and varicella vaccine as follows:

- $\mathbf{M}-\mathbf{M}-\mathbf{R}^{\circledast}$ II (live, attenuated combined measles, mumps and rubella vaccine), Merck Frosst Canada Ltd. (MMR vaccine)

- PRIORIX® (live, attenuated combined measles, mumps and rubella vaccine), GlaxoSmithKline Inc. (MMR vaccine)

- PRIORIX-TETRA ${ }^{\circledR}$ (live, attenuated combined measles, mumps, rubella and varicella vaccine), GlaxoSmithKline Inc. (MMRV vaccine) 


\section{Storage information for the measles vaccine:}

Storage temperature needs to be maintained during shipment. Products monographs should be consulted for the most up-to-date information.

$\mathbf{M}-\mathbf{M}-\mathbf{R}^{\circledast}$ II: Protect the vaccine from light. Before reconstitution, store the vial of vaccine at $+2^{\circ} \mathrm{C}$ to $+8^{\circ} \mathrm{C}$ or colder. The diluent may be stored in the refrigerator or at room temperature and must not be frozen.

PRIORIX ${ }^{\oplus}$ : Store in a refrigerator at $+2^{\circ} \mathrm{C}$ to $+8^{\circ} \mathrm{C}$. The diluent may be stored separately at room temperature. Protect from light.

PRIORIX-TETRA ${ }^{\oplus}$ : Store the vaccine and diluent in a refrigerator at $+2^{\circ} \mathrm{C}$ to $+8^{\circ} \mathrm{C}$ and do not freeze. Protect the vaccine from light. Once reconstituted, administer vaccine promptly. If necessary, the reconstituted vaccine may be stored in a refrigerator at $+2^{\circ} \mathrm{C}$ to $+8^{\circ} \mathrm{C}$ for up to 8 hours.

Once reconstituted, all vaccines should be administered promptly. If necessary, the reconstituted vaccine may be stored in a refrigerator at $+2^{\circ} \mathrm{C}$ to $+8^{\circ} \mathrm{C}$ for up to 8 hours.

\subsection{OUTBREAKS}

Supplementary efforts to achieve high immunization coverage against measles should be considered and public health interventions such as immunization campaigns should be adapted to the particular outbreak and its extent in the community. The extensiveness of an immunization campaign should be determined based on the public health objective (no secondary cases or limit spread in the community), the feasibility of the intervention, and the level of risk in the community. These include efforts to reduce missed opportunities for measles immunization, increased access to measles immunization campaigns (mop-up) or even catch-up campaigns to immunize individuals not considered fully immunized against measles according to the current $\mathrm{NACl}$ recommendations as well as outreach efforts to sensitize the population to the importance of being immunized against measles. Measles vaccine coverage should be monitored closely and vaccine uptake should be thoroughly documented for different population groups as well as at the individual level. 


\section{STRATEGIC RISK COMMUNICATIONS}

\subsection{BACKGROUND}

The goal of the risk communications chapter is to ensure that all partners involved in the prevention and control of measles outbreaks in Canada collaborate to deliver consistent, complementary, and effective communication that meets the needs of the public and stakeholders.

This chapter outlines communications protocols for the $\mathrm{F} / \mathrm{P} / \mathrm{T}$ levels as well as tools that can be adapted by all users of these guidelines to assist in the implementation of risk communications practices.

\subsubsection{RISK COMMUNICATIONS OBJECTIVE}

To engage in timely and appropriate communications activities coordinated among all partners to help promote the adoption of infection control measures and reinforce trust among the public.

\subsection{F/P/T COMMUNICATIONS PROTOCOLS}

In a measles outbreak situation, communications protocols between federal, provincial and territorial governments are essential to ensure:

- A clear understanding of communication roles and responsibilities between partners involved in the outbreak response.

- Efficient relationships and information-sharing and planning processes among communications staff of involved partners.

- Efficient and effective use of communication resources.

\subsection{ROLES AND RESPONSIBILITIES}

The roles and responsibilities for the communications around a measles outbreak mirror those established for the management of any outbreak. If the outbreak is limited to one province or territory, that jurisdiction is responsible for leading the communications. If the outbreak spreads to affect more than one province or territory, the Public Health Agency of Canada leads public communications in collaboration with the affected jurisdictions. The Agency also leads public communications during outbreaks that affect conveyances (trains, buses, airlines, cruise ships and cargo vessels in international waters), as the Agency is the lead for communicating internationally about a measles outbreak in Canada.

Regardless of the communications lead, information sharing during an outbreak is essential in order to ensure coordinated communications across all jurisdictions. Therefore, the following steps are recommended:

1. As soon as an outbreak (as defined by these guidelines) is identified, the Public Health Agency of Canada's Measles lead should share the information with the Public Health Communications Directorate.

2. The Agency will be responsible for informing all provincial/territorial communications partners via the Public Health Network (PHN) Communications Network. This information will be shared via email.

3. As necessary, the Public Health Agency of Canada will organize teleconferences for the PHN Communications Network to update on the situation. All communications materials should be shared for information with the Working Group.

4. When the Agency is not the communications lead, provincial and territorial communications partners will endeavour to share their communications products with the Agency for distribution to the PHN Communications Network before making public announcements. 
When the Agency leads on outbreak communications, it will develop public communications material in consultation with the PHN Communications Network, and distribute the final products with its members before making them public whenever possible.

In addition to sharing messages and communications products, the lead organization can also use the PHN Communications Network as a resource to plan coordinated communications activities. This group already meets monthly, but additional meetings can be scheduled in order to specifically address the communications needs for outbreak control.

\subsection{EVALUATION}

Formal and informal evaluations (ongoing and postoutbreak) are made based on the objectives set at the beginning of the risk communications strategy. A variety of evaluation activities can be undertaken.

The post-outbreak evaluation of communications plans and the activities will be undertaken by the lead organization, in order to inform future planning and improve future response. This could be done after available action reviews from the active players have been gathered and analysed.

For more information on risk communications and the evaluation process, please refer to the Health Portfolio's Strategic Risk Communications Framework at: www.phac-aspc.gc.ca/publicat/2007/risk-com/ index-eng.php.

\subsection{RISK COMMUNICATIONS KEY PRINCIPLES}

\section{TRANSPARENCY}

Communications is often the first line of public-health intervention, especially in the context of an outbreak. Information about the cases, potential exposure risks, and infection prevention and control measures (hand washing, staying home when sick, and monitoring for symptoms) can be an effective way to reduce the spread of infection before medical interventions, such as vaccines, are available.
In a measles outbreak, the best practice is to inform the public as soon as possible after a case is identified. In accordance with the F/P/T protocols above, jurisdictions will alert the Agency before publicly announcing an outbreak.

\section{STAKEHOLDER RELATIONS}

Engaging stakeholders in risk communications and risk management is highly beneficial for measles outbreak communications, because it helps ensure coordinated, consistent messages and communication approaches that meet the needs of the stakeholders. It also affords the opportunity to leverage the valuable resources and information that stakeholders can offer.

In order to help prioritize stakeholders, the Agency uses a stakeholder map (Refer to Appendix I). This categorizes stakeholders by the degree to which they are impacted by the risk issue, and the degree to which they have an impact on the mitigation of the risk.

\section{EFFECTIVE KEY MESSAGING FOR MEASLES OUTBREAKS}

The following are general messages that could be useful in any measles outbreak:

- Measles is a highly infectious disease. Its symptoms include fever, red eyes, runny nose, drowsiness, irritability and a red blotchy rash that begins on the face.

- Measles affects all age groups but generally the disease is more severe in infants and adults. Measles during pregnancy can result in a higher risk of premature labour and low infant birth weights.

- Immunization is the best defence against this disease. Canadians are reminded to keep all vaccinations up-to-date.

- People who may have been exposed, who are not immunized and are experiencing symptoms should contact their health care provider or public health authority to determine the best course of action. As a general rule, people who are sick should stay at home to reduce the risk of spreading an infectious disease. 


\section{MESSAGE FRAMING}

To help prepare effective risk messages beyond building awareness of the outbreak and appropriate infection prevention and control, the Agency has developed a Message Framing Tool (Refer to Appendix J) which outlines the key elements of an effective risk message.

The elements that are unique to risk messaging include:

- using evidence to support all risk/benefit claims

- acknowledging uncertainty

- communicating actions to take to prevent illness

\section{LISTENING AND STAKEHOLDER PERCEPTIONS}

Risk communications literature indicates that the public's perception of risk has just as much influence over their behaviour, as the actual risk $(41,42)$. For example, if people who are at high risk for measles infection do not feel that they are at risk, they are unlikely to take any action to protect themselves against it.

- In a measles outbreak, monitoring stakeholder perceptions can help organizations to better understand what misunderstandings the public may have about the outbreak, and what barriers may influence their acceptance and adoption of public health advice. This can be accomplished through: Scan social media activity (i.e. Facebook, Twitter, blogs and forums) to identify what questions, concerns, and opinions the public may have about the outbreak.

- Review communications material from organizations and governments to look for points of confusion or conflict.

- Place calls to stakeholders to find out what issues are being raised through their networks.

- Conduct focus testing, public opinion research, town halls and external advisory groups to better understand the public's perception of risk.
By incorporating these key risk communications principles, and ensuring coordination between all partners in managing the outbreak, we can create a communications response that better meets the needs of those at risk, and ultimately serves the end goal of preventing and controlling measles outbreaks. 


\section{ANALYZE THE OUTBREAK}

As the outbreak progresses, a descriptive analysis (person, place, and time) should be ongoing. The analysis should be conducted by the lead organization responsible for the outbreak investigation. Depending on the nature of the outbreak, these analyses could be shared with other P/Ts and the Agency via the CNPHI at www.cnphi-rcrsp.ca, or other established mechanisms.

At the conclusion of the outbreak, the nature of the outbreak should be fully analyzed and reported. The lead jurisdiction should produce a report within one year of the outbreak conclusion and make this report publicly available to other jurisdictions in Canada so that they can learn from recent experience. It is recommended that the following data elements be evaluated $(4,6)$ :

- the total number of cases and incidence rate of infection;

- an epidemiologic description of the index case

- analysing and understanding the chains of transmission (including the number of cases in each chain);

- analysis of case classification (imported, import-related, unknown, epidemiological link to unknown source case);

- analysis of demographic characteristics;

- identification of risk factors or groups most affected; assessment of regional vaccination coverage;

- identification of the number of preventable cases;

- characterization of case susceptibility (cases too young to be immunized, cases born before 1970, cases not immunized as per $\mathrm{NACl}$ recommendations, cases with medical contraindication to immunization, cases with documented philosophical/religious exemption, primary and secondary vaccine failure); and

- consider estimating the effective reproductive number.
If the size of the outbreak is sufficient, the jurisdiction could also assess:

- the effectiveness of the infection prevention and control measures.

- vaccine efficacy by comparing attack rates of immunized and unimmunized cases. 


\section{REFERENCES}

(1) Public Health Agency of Canada: Routine practices and additional precautions for preventing the transmission of infection in healthcare settings. May 2013.

(2) National Advisory Committee on Immunization (NACl). Statement on Measles-Mumps-Rubella-Varicella Vaccine. CCDR Sept 2010; 36(ACS-9).

(3) Dallaire F, De Serres G, Tremblay FW, Markowski F, Tipples G. Long-lasting measles outbreak affecting several unrelated networks of unvaccinated persons. J Infect Dis 2009 Nov 15;200(10):1602-1605.

(4) Pan-American Health Organization (PAHO). Measles elimination field guide. 2005; Available at: www1.paho.org/english/ad/fch/im/fieldguide_ measles.pdf

(5) Public Health Agency of Canada. Case definitions for diseases under national surveillance. CCDR Nov 2009; 35(S2).

(6) World Health Organization. World Health Organization. Measles fact sheet $N^{\circ} 286$. 2012; Available at: www.who.int/mediacentre/factsheets/ fs286/en. Accessed October, 2011.

(7) Nicoara C, Zach K, Trachsel D, German D, Matter L. Decay of passively acquired maternal antibodies against measles, mumps and rubella viruses. Clin Diagn Lab Immunol 1999;6(6):868.

(8) National Advisory Committee on Immunization (NACl). Canadian immunization guide. Part 4: Active Vaccines-Measles Vaccine. 2012; Available at: www.phac-aspc.gc.ca/publicat/cig-gci/p04meas-roug-eng.php. Accessed December, 2012.

(9) World Health Organization. Guidelines for prevention and control. Second Edition. 2006.

(10) Heymann DL,MD. Control of communicable diseases manual. 19th ed.: American public health association; 2008. p. 403.

(11) Public Health Agency of Canada. What you need to know about measles. 2011; Available at: www.phac-aspc.gc.ca/im/iyc-vve/faq-dis-mal/ measles-rougeole-eng.php. Accessed November 9, 2011.

(12) Manikkavasagan G, Ramsay M. The rationale for the use of measles post-exposure prophylaxis in pregnant women: A review. J Obstet Gynaecol 2009;29(7):572.
(13) Atmar RL, Englund JA, Hammill H. Complications of measles during pregnancy. Clin Infect Dis 1992;14(1):217.

(14) Soldatou A, Graham Davis E. Respiratory virus infections in the immunocompromised host. Paediatr Respir Rev 2003;4(3):193.

(15) Couch RB, Englund JA. Respiratory viral infections in immunocompetent and immunocompromised persons. Am J Med 1997;102(3):2.

(16) American Academy of Pediatrics. Measles. In: Pickering L, Baker C, editors. Red book: 2012 report of the committee on infectious diseases. $29^{\text {th }}$ ed. Elk Grove Village, IL: American Academy of Pediatrics; 2012. p. 489-499.

(17) Chen RT, Orenstein WA, Frank JA, Sacks JJ, Dales LG, Preblud SR, et al. An explosive pointsource measles outbreak in a highly vaccinated population. Am J Epidemiol 1989;129(1):173.

(18) Davis RM, Orenstein WA, Frank JA, Sacks JJ, Dales LG, Preblud SR, et al. Transmission of measles in medical settings, 1980 through 1984. JAMA 1986;255:1295.

(19) Dales LG, Kizer KW. Measles transmission in medical facilities. West J Med 1985;142:415.

(20) Remington PL, Hall WN, Davis IH, Herald A, Gunn RA. Airborne transmission of measles in a physician's office. JAMA 1985;75:676.

(21) Bloch AB, Orenstein WA, Ewing MW. Measles outbreak in a pediatric practice: airborne transmission in an office setting. Pediatrics 1985;75:676.

(22) Istre GR, McKee PA, West, G.R., O'Mara, D.J., Rettig PJ, Stuemky J, et al. Measles spread in hospital settings: an important focus of disease transmission? Pediatrics 1987;79:356.

(23) Sienko DG, Friedman C, McGee HB, Allen MJ, Simeson WF, Wentworth BB, et al. A measles outbreak at university medical setting involving medical health care providers. Am J Public Health 1987; 15:201.

(24) Watkins NM, Smith RP, St. Germain DL, MacKay DN. Measles (rubeola) infection in a hospital setting. Am J Infect Control 1987;15:201. 
(25) Raad II, Sheretz RJ, Rains CS, Cusick JL, Fauerbach LL, Reuman PD, et al. The importance of nosocomial transmission in the propagation of a community outbreak. Infect Control Hosp Epidemiol 1989;10:161.

(26) Rank EL, Brettman L, Katz-Pollack H, DeHertogh D, Nevill D. Chronology of a hospital-wide measles outbreak: lessons learned and shared from an extraordinatory week in late March 1989. Am J Infect Control 1992;209:315.

(27) Atkinson WL. Measles and health care workers. Infect Control Hosp Epidemiol 1994;15:5.

(28) Botelho-Nevers E, Cassir N, Minodier P, Laporte R, Gautret P, Badiaga S, et al. Measles among healthcare workers: A potential for nosocomial outbreaks. Eurosurveillance 2011;16(2):1.

(29) Public Health Agency of Canada. Infection control guidelines: prevention and control of occupational infections in health care. Canadian Communicable Disease Report 2002;28(S1).

(30) Canadian Standards Association. Z317.2-10 Special requirements for heating, ventilation and air conditioning (hvac) systems in health care facilities. 2001.

(31) Canadian Standards Association. Z8000 Canadian health care facilities-planning, design and construction. 2001.

(32) Cutts F, Brown D. The contribution of field tests to measles surveillance and control: A review of available methods. Rev Med Microbiol 1995;5(1):35.

(33) World Health Organization. Manual for the laboratory diagnosis of measles and rubella virus infection. 2007;2.

(34) Bellini WJ, Icenogle J. Measles and rubella viruses. Manual of clinical microbiology. $10^{\text {th }}$ ed. Washington DC: ASM Press; 2011.

(35) Tipples G, Hiebert J. Detection of measles, mumps and rubella viruses. Methods in Molecular Biology 2011;665:183.

(36) Hickman CJ, Hyde TB, Sowers SB, Mercader S, McGrew M, Williams NJ, et al. Laboratory characterization of measles virus infection in previously vaccinated and unvaccinated individuals. J Infect Dis 2011 Jul;204 Suppl 1:S549-58.

(37) Rota JS, Hickman CJ, Sowers SB, Rota PA, Mercader S, Bellini WJ. Two case studies of modified measles in vaccinated physicians exposed to primary measles cases: high risk of infection but low risk of transmission. J Infect Dis 2011 Jul;204 Suppl 1:S559-63.
(38) Cohen B, Audet S, Andrews N, Beeler J, WHO working group on measles plaque reduction neutralization test. Plaque reduction neutralization test for measles antibodies: Description of a standardised laboratory method for use in immunogenicity studies of aerosol vaccination. Vaccine 2007;26(1):59-66.

(39) Markowitz LE, Sepulveda J, Diaz-Ortega J, Valdespino J, Albrecht $P$, Zell E, et al. Immunization of six-month-old infants with different doses of Edmonston-Zagreb and Schwarz measles vaccines. N Engl J Med 1990;322(9):580-7.

(40) Chen RT, Markowitz LE, Albrecht P, Stewart JA, Mofenson LM, Preblud SR, et al. Measles antibody: reevaluation of protective titers. J Infect Dis 1990 Nov;162(5):1036-1042.

(41) Carman KG, Koorman P. Flu shots, mammograms and the perception of probabilities. Institute for the study of labour 2011;5739(1):1.

(42) Setbon M, Le Pape M, Letroublon C, Caille-Brillet A, Raude J. The public's preventive strategies in response to the pandemic influenza a/H1N1 in France: distribution and determinants. Prev Med 2011;52(2):178.

(43) Pan American Health Organization (PAHO). Meeting of the panel of experts for the documentation and verification of measles, rubellal, and CRS elimination. Immunization Newsletter 2009;31(2):1.

(44) Hutse V, Van Hecke K, De Bruyn R, Samu O, Lernout T, Muyembe JJ, et al. Oral fluid for the serological and molecular diagnosis of measles. Int J Infect Dis 2010 Nov;14(11):e991-7.

(45) Gark R. Subacute sclerosing panencephalitis. Postgrad Med J 2002;78:63.

(46) Hummel KB, Lowe L, Bellini WJ, Rota PA. Development of quantitative gene-specific real-time RT-PCR assays for the detection of measles virus in clinical specimens. J Virol Methods 2006 Mar;132(1-2):166-173.

(47) Expanded Programme on Immunization (EPI). Standardization of the nomenclature for describing the genetic characteristics of wild-type measles viruses. Wkly Epidemiol Rec 1998;73(36):265. 


\section{APPENDIX A. PERSONS INVOLVED IN DEVELOPING THE GUIDELINES}

MEASLES AND RUBELLA ELIMINATION WORKING GROUP (MREWG)

Gaston DeSerres, Tony Mazzulli, Monika Naus, Marina Salvadori

\section{HEALTH CANADA}

Gillian Badger, Sahadia Etienne

\section{PUBLIC HEALTH AGENCY OF CANADA}

Arlette Alcazar, Frederic Bergeron, Heather Deehan, Tracie EisBrenner, Joanne Hiebert, Nashira Khalil, Jacqueline Kosche, Julie Laroche, Mark Lysyshyn, Julie McGihon, Teresa Mersereau, Rana Nemr, Carole Nesbeth, Laurie O’Neil, Joy Pulickal, Myriam Saboui, Alberto Severini, Amanda Shane, Lindsey Sherrard, Lindsey Williams 


\section{APPENDIX B. PROVINCIAL/TERRITORIAL LEGISLATURES FOR REPORTING COMMUNICABLE DISEASES}

\begin{tabular}{|c|c|c|c|}
\hline PROVINCE/TERRITORY & NAME OF LEGISLATION & LAST UPDATED & SECTION \\
\hline Alberta & Public Health Act & 2010 & $\begin{array}{l}\text { Part 3, Section 22, Section } 23 \text { Notification } \\
\text { of communicable disease }\end{array}$ \\
\hline British Columbia & Public Health Act & 2008 & $\begin{array}{l}\text { Division } 3 \text {, Section } 10 \text { Mandatory reporting } \\
\text { of infection or exposure }\end{array}$ \\
\hline Manitoba & Public Health Act & 2009 & $\begin{array}{l}\text { Part 4, Division } 1 \text { Reporting Requirements } \\
\text { for Diseases }\end{array}$ \\
\hline New Brunswick & Public Health Act & 2009 & $\begin{array}{l}\text { Part 3, Section } 27 \text { Reporting of notifiable } \\
\text { diseases and other information }\end{array}$ \\
\hline $\begin{array}{l}\text { Newfoundland and } \\
\text { Labrador }\end{array}$ & NL Communicable Diseases Act & 2006 & $\begin{array}{l}\text { Section } 4 \text {, Section } 5 \text { Notice by physician, } \\
\text { notice by others }\end{array}$ \\
\hline Northwest Territories & Public Health Act & 2009 & Sections 6-10 Disease Surveillance Regulations \\
\hline Nova Scotia & Health Protection Act & 2004 & Section 31 Notifiable Diseases or Condition \\
\hline Nunavut & Public Health Act & 2008 & $\begin{array}{l}\text { Section 2, 3, } 4 \text { Communicable Diseases } \\
\text { Regulations }\end{array}$ \\
\hline Ontario & Health Protection and Promotion Act & 2009 & Section 2 Reporting of Infectious Diseases \\
\hline Prince Edward Island & Public Health Act & 2010 & Section 23 Regulations \\
\hline Quebec & Loi sur la santé publique & 2012 & $\begin{array}{l}\text { Chapter VIII Intoxications, infections et maladies } \\
\text { à déclaration obligatoire }\end{array}$ \\
\hline Saskatchewan & Public Health Act & 1994 & Part 2 Reporting of Communicable Diseases \\
\hline Yukon & Public Health and Safety Act & 2002 & Section 2 Public health and sanitation regulations \\
\hline
\end{tabular}

SOURCE: http://206.214.221.35. NDDB Database March 12, 2012 


\section{APPENDIX C. \\ FEDERAL/PROVINCIAL/TERRITORIAL \\ MEASLES REPORTING REQUIREMENTS}

\begin{tabular}{|c|c|c|c|c|}
\hline JURISDICTION & REPORT FORM & REPORT TO & TIMELINE & REQUIREMENT \\
\hline \multirow[t]{5}{*}{ Alberta } & $\begin{array}{l}\text { Physicians/Health Practitioner } \\
\text { and others }\end{array}$ & Medical Officer of Health (AB) & 1 hour & Mandatory \\
\hline & $\begin{array}{l}\text { All Laboratories (regional and } \\
\text { provincial) } A B\end{array}$ & Chief Medical Officer of Health (AB) & 1 hour & Mandatory \\
\hline & $\begin{array}{l}\text { All Laboratories (regional and } \\
\text { provincial) } A B\end{array}$ & Medical Officer of Health (AB) & 1 hour & Mandatory \\
\hline & $\begin{array}{l}\text { All Laboratories (regional and } \\
\text { provincial) } A B\end{array}$ & Attending/Ordering Physician & 1 hour & Mandatory \\
\hline & Medical Officer of Health (AB) & Chief Medical Officer of Health (AB) & 1 hour & Mandatory \\
\hline \multirow[t]{2}{*}{ British Columbia } & $\begin{array}{l}\text { Physicians/Health Practitioner } \\
\text { and others }(\mathrm{BC})\end{array}$ & $\begin{array}{l}\text { BCCDC (British Colombia Communicable } \\
\text { Disease Control) }\end{array}$ & 1 hour & Mandatory \\
\hline & Laboratory BC & $\begin{array}{l}\text { BCCDC (British Colombia Communicable } \\
\text { Disease Control) }\end{array}$ & 1 hour & Mandatory \\
\hline \multirow[t]{4}{*}{ Manitoba } & $\begin{array}{l}\text { All Laboratories (regional and } \\
\text { provincial) MB }\end{array}$ & $\begin{array}{l}\text { Manitoba Health Public Health } \\
\text { Surveillance Unit }\end{array}$ & 1 hour & Mandatory \\
\hline & $\begin{array}{l}\text { Regional laboratories } \\
\text { Manitoba }\end{array}$ & Cadham Provincial Laboratory (CPL) & 7 days & Mandatory \\
\hline & $\begin{array}{l}\text { Physicians/Health Practitioner } \\
\text { and others }\end{array}$ & CPHO (Chief Public Health Officer) MB & 1 hour & Mandatory \\
\hline & $\begin{array}{l}\text { All Laboratories (regional and } \\
\text { provincial) MB }\end{array}$ & $\mathrm{CPHO}$ (Chief Public Health Officer) MB & 1 hour & Mandatory \\
\hline New Brunswick & $\begin{array}{l}\text { Physicians/Health Practitioner } \\
\text { and others }\end{array}$ & MOH (Medical Officer of Health) & 1 hour & Mandatory \\
\hline \multirow{3}{*}{$\begin{array}{l}\text { Newfoundland and } \\
\text { Labrador }\end{array}$} & Health Care Practitioners & Regional Medical Officer of Health (NL) & 1 hour & Mandatory \\
\hline & $\begin{array}{l}\text { Provincial Public Health } \\
\text { Laboratory (NL) }\end{array}$ & Regional Medical Officer of Health (NL) & 1 hour & Mandatory \\
\hline & $\begin{array}{l}\text { Regional Medical Officer } \\
\text { of Health (NL) }\end{array}$ & Provincial Office (NL) & 1 hour & Mandatory \\
\hline Northwest Territories & $\begin{array}{l}\text { Physicians/Health Practitioner } \\
\text { and others }\end{array}$ & Chief Public Health Officer (NT) & 24 hours & Mandatory \\
\hline \multirow[t]{3}{*}{ Nova Scotia } & $\begin{array}{l}\text { Physicians/Health Practitioner } \\
\text { and others (NS) }\end{array}$ & Medical Officer of Health (MOH) NS & 1 hour & Mandatory \\
\hline & School Principal NS & Medical Officer of Health (MOH) NS & 1 hour & Mandatory \\
\hline & Institution administrator & Medical Officer of Health (MOH) NS & 1 hour & Mandatory \\
\hline Nunavut & $\begin{array}{l}\text { Physicians/health practitioner } \\
\text { and others NU }\end{array}$ & Chief Medical Health Officer (CMHO) NU & 1 hour & Mandatory \\
\hline \multirow[t]{4}{*}{ Ontario } & $\begin{array}{l}\text { Physicians/Health Practitioner } \\
\text { and others }\end{array}$ & Medical Officer of Health (MOH) ON & hours & Mandatory \\
\hline & Hospital Administrator $\mathrm{ON}$ & Medical Officer of Health $(\mathrm{MOH}) \mathrm{ON}$ & hours & Mandatory \\
\hline & Laboratory Operator ON & Medical Officer of Health (MOH) ON & hours & Mandatory \\
\hline & School Principal ON & Medical Officer of Health $(\mathrm{MOH}) \mathrm{ON}$ & hours & Mandatory \\
\hline Prince Edward Island & $\begin{array}{l}\text { Physicians/health practitioner } \\
\text { and others PEI }\end{array}$ & Chief Health Officer PEI & hours & Mandatory \\
\hline
\end{tabular}




\begin{tabular}{|c|c|c|c|c|}
\hline JURISDICTION & REPORT FORM & REPORT TO & TIMELINE & REQUIREMENT \\
\hline \multirow[t]{2}{*}{ Quebec } & Laboratories (QC) & Regional public health director $(\mathrm{CC})$ & 48 hours & Mandatory \\
\hline & Doctors (QC) & Regional public health director (OC) & 48 hours & Mandatory \\
\hline \multirow[t]{3}{*}{ Saskatchewan } & Laboratory (all) SK & Medical Health Officer MHO Saskatchewan & 48 hours & Mandatory \\
\hline & Teacher/Principal SK & Medical Health Officer MHO Saskatchewan & 48 hours & Mandatory \\
\hline & $\begin{array}{l}\text { Physicians/Health Practitioner } \\
\text { and other SK }\end{array}$ & Medical Health Officer MHO Saskatchewan & 48 hours & Mandatory \\
\hline Yukon & $\begin{array}{l}\text { Physicians/health practitioner } \\
\text { and others YT }\end{array}$ & $\begin{array}{l}\text { Yukon Communicable Disease } \\
\text { Control (YCDC) }\end{array}$ & 1 hour & Mandatory \\
\hline Federal & $\begin{array}{l}\text { Provincial/territorial } \\
\text { jurisdiction }\end{array}$ & $\begin{array}{l}\text { Canadian Notifiable Disease Surveillance } \\
\text { System, PHAC }\end{array}$ & Annual & Voluntary \\
\hline Federal & $\begin{array}{l}\text { Provincial/territorial } \\
\text { jurisdiction }\end{array}$ & $\begin{array}{l}\text { Canadian Measles and Rubella Surveillance } \\
\text { System, PHAC }\end{array}$ & 7 days & Voluntary \\
\hline Federal & $\begin{array}{l}\text { Public Health Agency of } \\
\text { Canada }\end{array}$ & Pan American Health Organization & 7 days & Voluntary \\
\hline
\end{tabular}




\section{APPENDIX D.}

\section{NATIONAL MEASLES CASE REPORT FORM}

Check one: a MEASLES a RUBELLA a CONGENITAL RUBELLA SYNDROME/INFECTION

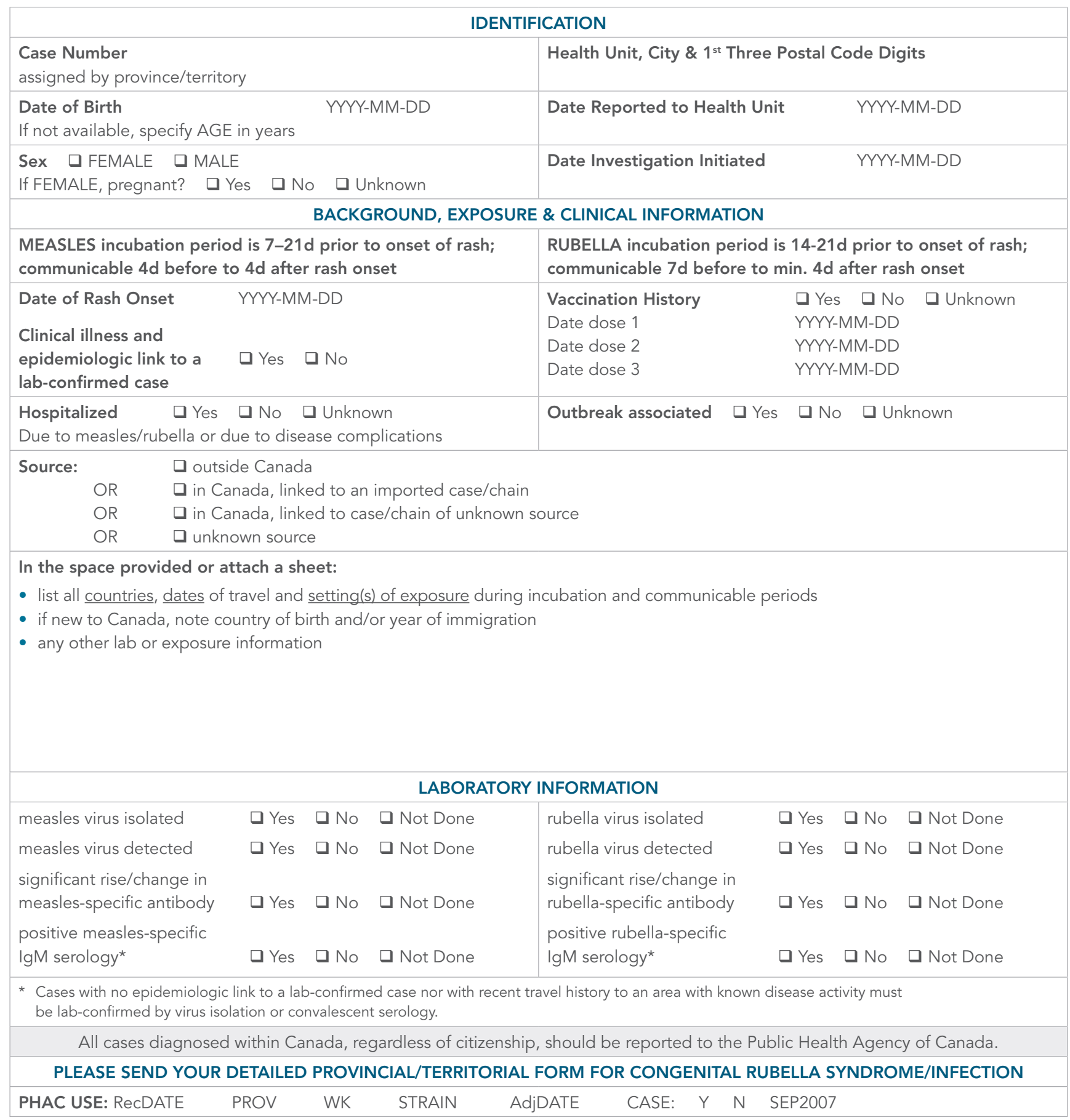




\section{APPENDIX E. \\ SAMPLE MEASLES CASE \\ INVESTIGATION FORM}

\section{Sample Measles Outbreak Case Investigation Form}

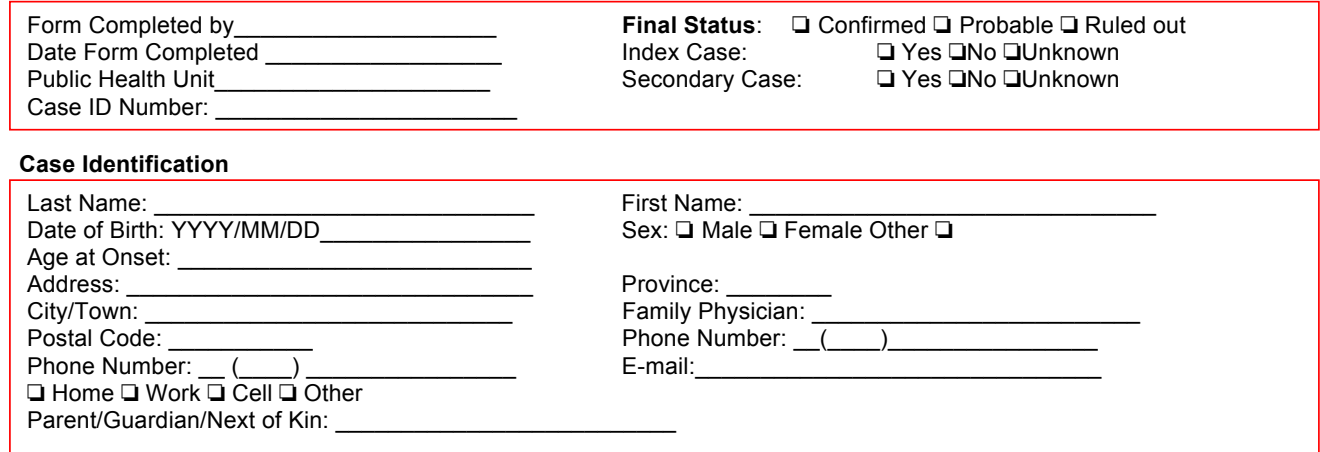

\section{Clinical Information}

Symptoms:

DMaculopapular Date of onset: Where did rash start? days

Is rash generalized? $\square$ Yes $\square$ No $\square$ Unknown

$\square$ Fever:

Date of onset: 1 Max Temp ${ }^{\circ} \mathrm{C}$

口Coryza

-Conjunctivitis

口Cough

口Pharyngitis

$\square$ Koplik's spots

口Light Sensitivity

DOther

$\square$ Oral $\square$ Rectal $\square$ Axillary

Hospitalization: $\square$ Yes $\square$ No $\square U n k n o w n$

If yes, Name of Hospital:

Date admitted:

Date discharged:

Attended Out-patient Clinic? $\square$ Yes $\square$ No $\square U n k n o w n$

If yes, Name of Clinic:

Date of visit:

Clinical Outcome:

$\square$ Recovered $\square$ without residual effects $\square$ with residual effects

$\square$ Residual effects:

$\square$ Otitis Media $\square$ Pneumoniae $\square$ Encephalitis $\square$ Meningitis $\square$ Bronchitis $\square$ Diarrhea $\square$ Other

$\square$ Fatal

Date of Death

Death Due to Measles/Complications: $\square$ Yes $\square$ No

口Unknown

Calculation of Incubation and Communicability Period

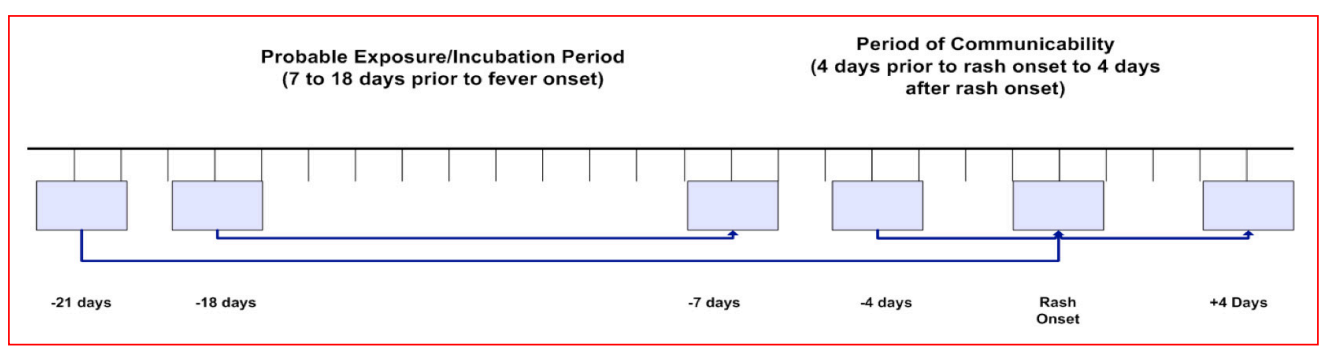


History of Immunization

History of measles disease: $\square$ Yes $\square$ No $\square$ Unknown

Received measles-containing vaccine in the past: $\quad \square$ Yes $\square$ No $\quad \square$ Unknown

If no immunization, specify reason:

\begin{tabular}{||l|l|l|l|l|}
\hline Vaccine Name & $\begin{array}{l}\text { Date Received } \\
\text { (YYYY/MM/DD) }\end{array}$ & $\begin{array}{l}\text { Age } \\
\text { (Yrs) }\end{array}$ & $\begin{array}{l}\text { Province/Territory/ } \\
\text { Or Country }\end{array}$ & $\begin{array}{l}\text { Lot Number } \\
\text { (if known) }\end{array}$ \\
\hline 1. & & & & \\
\hline 2. & & & & \\
\hline 3. & & & & \\
\hline
\end{tabular}

Laboratory Information

\begin{tabular}{|c|c|c|c|c|}
\hline & Sample 1 & Sample 2 & Sample 3 & Sample 4 \\
\hline Type of Sample & $\begin{array}{l}\square \text { Nasopharyngeal } \\
\text { aspirate/swab } \\
\square \text { Throat swab } \\
\square \text { Serum } \\
\square \text { Urine } \\
\square \text { Other: }\end{array}$ & $\begin{array}{l}\text { Nasopharyngeal } \\
\text { aspirate/swab } \\
\square \text { Throat swab } \\
\square \text { Serum } \\
\square \text { Urine } \\
\square \text { Other: }\end{array}$ & $\begin{array}{l}\square \text { Nasopharyngeal } \\
\text { aspirate/swab } \\
\square \text { Throat swab } \\
\square \text { Serum } \\
\square \text { Urine } \\
\square \text { Other: }\end{array}$ & $\begin{array}{l}\text { Nasopharyngeal } \\
\text { aspirate/swab } \\
\square \text { Throat swab } \\
\square \text { Serum } \\
\square \text { Urine } \\
\square \text { Other: }\end{array}$ \\
\hline \multicolumn{5}{|l|}{ Identification \# } \\
\hline Date taken & Day/Month/Year & Day/Month/Year & Day/Month/Year & Day/Month/Year \\
\hline \multicolumn{5}{|l|}{ Date Sent } \\
\hline \multicolumn{5}{|c|}{ FOR LABORATORY USE } \\
\hline Date Received & Day/Month/Year & Day/Month/Year & Day/Month/Year & Day/Month/Year \\
\hline \multicolumn{5}{|l|}{$\begin{array}{l}\text { Id \# in } \\
\text { laboratory }\end{array}$} \\
\hline Type of test & $\begin{array}{l}\square \text { IgM EIA capture } \\
\square \text { IgM EIA indirect } \\
\square \text { lgG EIA } \\
\square \text { Viral isolation } \\
\square \text { PCR } \\
\square \text { Other test }\end{array}$ & $\begin{array}{l}\text { IgM EIA capture } \\
\square \text { IgM EIA indirect } \\
\square \text { IgG EIA } \\
\square \text { Viral isolation } \\
\square \text { PCR } \\
\square \text { Other test }\end{array}$ & $\begin{array}{l}\square \text { IgM ElA capture } \\
\square \text { IgM EIA indirect } \\
\square \text { IgG EIA } \\
\square \text { Viral isolation } \\
\square \text { PCR } \\
\square \text { Other test }\end{array}$ & $\begin{array}{l}\square \text { IgM ElA capture } \\
\square \text { IgM EIA indirect } \\
\square \text { IgG EIA } \\
\square \text { Viral isolation } \\
\square \text { PCR } \\
\square \text { Other test }\end{array}$ \\
\hline Results & $\begin{array}{l}\square \text { Positive } \\
\square \text { Negative } \\
\square \text { Indeterminate } \\
\square \text { Inadequate sample } \\
\square \text { Not processed }\end{array}$ & $\begin{array}{l}\square \text { Positive } \\
\square \text { Negative } \\
\square \text { Indeterminate } \\
\square \text { lnadequate sample } \\
\square \text { Not processed }\end{array}$ & $\begin{array}{l}\text { Positive } \\
\square \text { Negative } \\
\square \text { Indeterminate } \\
\square \text { Inadequate } \\
\text { sample } \\
\square \text { Not processed }\end{array}$ & $\begin{array}{l}\square \text { Positive } \\
\square \text { Negative } \\
\square \text { Indeterminate } \\
\square \text { Inadequate sample } \\
\square \text { Not processed }\end{array}$ \\
\hline Results dates & Day/Month/Year & Day/Month/Year & Day/Month/Year & Day/Month/Year \\
\hline
\end{tabular}

\section{Exposure Information:}

Have you had contact with anyone who was told they have measles: $\quad \square$ Yes $\square$ No

If yes, Name of Person:

Social activities in the 7 days before case developed symptoms

\begin{tabular}{|l|c|c|}
\hline Social Activities in the past $\mathbf{7}$ days & $\begin{array}{c}\text { Date(s) } \\
\text { (YYYY/MM/DD) }\end{array}$ & Activity Details \\
\hline$\square$ Used public transit & & \\
\hline$\square$ Visited or volunteered at a hospital & & \\
\hline$\square$ Attended church/religious function & & \\
\hline$\square$ Attended family gathering & & \\
\hline$\square$ Attended meeting or conference & & \\
\hline$\square$ Attended concert, theatre or sporting event & & \\
\hline
\end{tabular}




\begin{tabular}{|l|l|l|}
\hline$\square$ Participated in shopping event & & \\
\hline$\square$ Participated in recreational activity & & \\
\hline$\square$ Dined at coffee shop/cafeteria/food court & & \\
\hline$\square$ Dined at restaurant & & \\
\hline$\square$ Patronised bar or night club & & \\
\hline$\square$ Other activities & $\begin{array}{c}\text { Date(s) } \\
\text { (YYYY/MM/DD) }\end{array}$ & \\
\hline Travel History in the past 7 days: & & \\
\hline$\square$ Domestic & & \\
\hline$\square$ International & & \\
\hline
\end{tabular}

\section{Occupational Information}

Occupation:

Name of Employer:

Day Care/School/Educational Institution

Do you attend a day care, school or post-secondary institution? $\square$ Yes $\square$ No

If YES, Name of School/Institution:

Timetable (Please attach if available)

Grade/Level/Year:

\section{Living Arrangements}

What type of residence do you live in?

$\square$ House $\square$ Apartment $\square$ University residence $\square$ Hotel/Motel $\square$ Group Home or Long-Term Care Facility $\square$ Other (please specify)

Do you live, room or share accommodation with anyone? $\square$ Yes $\square$ No

If YES, with how many people?

Do you receive home care? $\square$ Yes $\square$ No

\section{Close Contact Information}

Please list all close contacts, including your spouse, partner, siblings, children, family members, roommates and other people you live with

\begin{tabular}{|c|c|c|c|c|c|}
\hline $\begin{array}{c}\text { Contact Name } \\
\text { (Surname, Given Name) }\end{array}$ & $\begin{array}{l}\text { Contact } \\
\text { Phone } \\
\text { Number }\end{array}$ & Relationship & $\begin{array}{c}\text { Date of Birth } \\
\text { (YYYY/MM/DD) } \\
\text { or } \\
\text { Age }\end{array}$ & 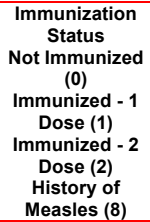 & Occupation \\
\hline & & & & & \\
\hline & & & & & \\
\hline & & & & & \\
\hline & & & & & \\
\hline
\end{tabular}

Comments/Notes:

\section{Classification}

Measles-laboratory confirmed

Measles probable case

Discarded

Basis for classification: $\square$ Laboratory results $\square$ Epidemiological link

Investigator:

$\square$
$\square$
Institution: $\square$ Epidemiological link $\square$ Clinical Presentation
Inte:




\section{APPENDIX F. RECOMMENDATIONS FOR THE MANAGEMENT OF MEASLES IN HEALTHCARE SETTINGS}

Healthcare settings include any facility or location where healthcare is provided and include emergency care, pre-hospital care, acute care, long term care, chronic/ complex care, home care, ambulatory care and other facilities or locations in the community where care is provided (e.g., infirmaries in schools, residential, and correctional facilities, etc.). Some healthcare settings may not have occupational health and infection prevention and control (IPC) departments. When these are mentioned, they refer to the individual(s) responsible for occupational health and IPC for that healthcare setting.

Healthcare workers ( $\mathrm{HCWs}$ ) include individuals who provide health care or support services such as nurses, physicians, dentists, nurse practitioners, paramedics and sometimes emergency first responders, allied health professionals, unregulated healthcare providers, clinical instructors, students, volunteers and housekeeping staff.

The term patients may apply to inpatients, outpatients, residents in long-term care/chronic care facilities, etc., and clients receiving care in the home and community settings.

\section{PRE-EMPLOYMENT OF HCWS}

1. Occupational health should document the HCW's immune status at the pre-employment examination. A HCW should be considered immune if:

a) $\mathrm{He} / \mathrm{she}$ has documentation of two doses of a measles-containing vaccine; or

b) $\mathrm{He} / \mathrm{she}$ has documentation of laboratory-confirmed measles; or

c) $\mathrm{He} /$ she has a positive measles IgG (refer to Section 7.0 and Appendix $\mathrm{H}$ for interpretation of IgG results).

\section{EXISTING HCWS}

1. Occupational health should provide MMR vaccine to all HCWs unless:

a) $\mathrm{He} / \mathrm{she}$ has documentation of two doses of a measles-containing vaccine; or

b) $\mathrm{He} / \mathrm{she}$ has documentation of laboratory-confirmed measles; or

c) $\mathrm{He} / \mathrm{she}$ has a positive measles IgG; or

d) $\mathrm{He} / \mathrm{she}$ has a valid contraindication to MMR vaccine.

\section{IPC MEASURES FOR SUSPECTED OR CONFIRMED MEASLES}

1. Healthcare settings should be notified when measles cases are present in the community and provided with information on clinical recognition and laboratory diagnosis of suspected cases.

2. Emergency departments and ambulatory care settings should be advised to triage suspected patients as expeditiously as possible into an airborne infection isolation room (AIIR) to avoid exposure to contacts in waiting rooms.

3. Outpatient clinics and home care organizations should have a system in place to identify patients with suspected or confirmed measles.

4. Outpatient clinic appointments should be postponed for suspected or confirmed measles patients unless there is access to an AIIR.

\section{HCWS WHO ARE SUSPECTED OR CONFIRMED MEASLES CASES}

1. HCWs that are suspected to have measles should be managed as confirmed cases until laboratory evidence suggests otherwise.

2. Cases should be advised to immediately notify occupational health and/or IPC for the facility in which they work. 
3. Information should be provided to HCWs on measles disease and its symptoms.

4. Cases should be advised to stay home for at least four days after the appearance of rash.

5. Cases should be advised to contact occupational health and/or IPC for their facility to determine fitness to return to work.

6. Cases should be reported to local public health authorities as per organizational policy.

\section{HCWS WHO ARE CONTACTS (EXPOSED TO MEASLES)}

For contact in the community (Refer to Section 4.2) and contact in the healthcare setting (i.e., contacts are individuals who have spent any length of time in a room or enclosed space while the individual with infectious measles was present for up to 2 hours after that individual left the room/space):

1. HCWs should be advised to immediately notify occupational health and/or IPC for the facility in which they work.

2. HCWs should be provided with information on measles contact.

3. HCWs should be provided with information on measles disease and its symptoms.

4. HCWs should be assessed for history of immune deficiency and current pregnancy status (refer to 7.c).

5. HCWs should be assessed for immunity to measles, if not assessed at pre-employment. HCWs are immune when:

a) $\mathrm{He} / \mathrm{she}$ has documentation of 2 doses of a measles-containing vaccine; or

b) $\mathrm{He} / \mathrm{she}$ has documentation of laboratory-confirmed measles; or,

c) $\mathrm{He} / \mathrm{she}$ has a positive measles lgG.

6. Susceptible contacts should be excluded from any work in the healthcare setting from the fifth day to the $21^{\text {st }}$ day after the last exposure regardless of whether the HCW received measles vaccine or immune globulin after the exposure.
7. Exposed HCWs who do not have documentation of measles at their pre-employment immunity assessment should be managed by:

a) Drawing blood for measles IgG serology;

b) Providing a dose of MMR vaccine (immediately after specimen taken) unless a contraindication to vaccination exists;

c) Considering the administration of immune globulin within six days of exposure in seronegative $\mathrm{HCW}$ s who are pregnant or severely immunocompromised (29);

d) Excluding HCW from work for the period of communicability from the fifth day to the $21^{\text {st }}$ day after the last exposure, unless serology results indicate immunity to measles; and

e) Referring to Section 7.0 and Appendix H for interpretation of IgG results:

(i) If IgG positive, then consider immune and can return to work.

(ii) If IgG negative, then consider susceptible, provide a second dose of MMR vaccine 28 days after the first and exclude from work from the fifth day to the $21^{\text {st }}$ day after the last exposure.

\section{PATIENTS WHO ARE SUSPECTED OR CONFIRMED MEASLES CASES}

1. Patients who are suspected to have measles are managed as confirmed cases until laboratory evidence suggests otherwise.

2. Patients should be isolated immediately in an AIIR.

3. If an AIIR is not available (e.g., in long-term care facilities, etc.) patients should be placed in a single room away from susceptible patients until transfer to a facility with an AIIR can be arranged.

4. Only immune HCWs should enter the room of a measles case or the room of a susceptible exposed patient who is in the infectious period. In circumstances when this is unavoidable, the non-immune HCW should wear a respirator.

5. Outpatient clinic appointments should be postponed for suspected or confirmed measles patients unless there is access to an AlIR. 
6. Home care patients with suspected or confirmed measles should be cared for only by measles immune HCWs.

7. IPC/HCWs should provide information on measles disease and its symptoms to the patients and their families.

8. Inpatients should remain in AIIR for at least four days after the appearance of rash. Immunocompromised patients with measles should remain in AIIR for the duration of their measles symptoms.

9. Cases should be reported to local public health as per organizational policy.

\section{PATIENTS WHO ARE CONTACTS (EXPOSED TO MEASLES)}

For contacts in the community (refer to Section 4.2) and contacts in the healthcare setting (i.e., contacts are individuals who have spent any length of time in a room or enclosed space while the individual with infectious measles was present for up to 2 hours after that individual left the room/space).

1. The healthcare facility should advise IPC and provide information on possible measles contact.

2. IPC should provide information on measles disease and its symptoms to the individual and HCWs.

3. IPC should assess for history of immunocompromise and current pregnancy status (refer to 6.c).

4. IPC should assess measles immunity of exposed patients. Consider immunity to measles when:

a) $\mathrm{He} / \mathrm{she}$ has documentation of two doses of a measles-containing vaccine; or

b) $\mathrm{He} / \mathrm{she}$ has documentation of laboratory-confirmed measles; or

c) $\mathrm{He} / \mathrm{sh}$ has a positive measles IgG (refer to Section 7.0 and Appendix G for interpretation of lgG results).

5. Susceptible patients who are contacts should be isolated in the healthcare setting from the fifth day to the $21^{\text {st }}$ day after the last exposure regardless of whether they received measles vaccine or immune globulin after the exposure.
6. Exposed patients who do not have documentation of measles immunity should be managed by:

a) Drawing blood for measles IgG serology;

b) Providing a dose of MMR vaccine (immediately after specimen taken) unless a contraindication to vaccination exists;

c) Considering the administration of immune globulin within six days of exposure in the seronegative patients who are pregnant or severely immunocompromised;

d) Isolating the exposed patients for the period of communicability from the fifth day to the $21^{\text {st }}$ day after the last exposure, unless serology results indicate immunity to measles; and

e) Referring to Section 7.0 and Appendix $\mathrm{H}$ for interpretation of IgG results,

(i) If IgG positive, then consider immune and isolation not required.

(ii) If IgG negative, then consider susceptible, provide a second dose of MMR vaccine 28 days after the first and isolate in an AlIR from the fifth day to the $21^{\text {st }}$ day after the last exposure.

\section{OUTPATIENTS OR DISCHARGED PATIENTS WHO ARE CONTACTS (EXPOSED TO MEASLES)}

1. IPC should advise local public health authorities of outpatients or discharged patients who are contacts. 


\section{APPENDIX G. ALGORITHMS FOR HEALTH CARE SETTINGS}

Algorithm A. Assessing healthcare workers' susceptibility to measles

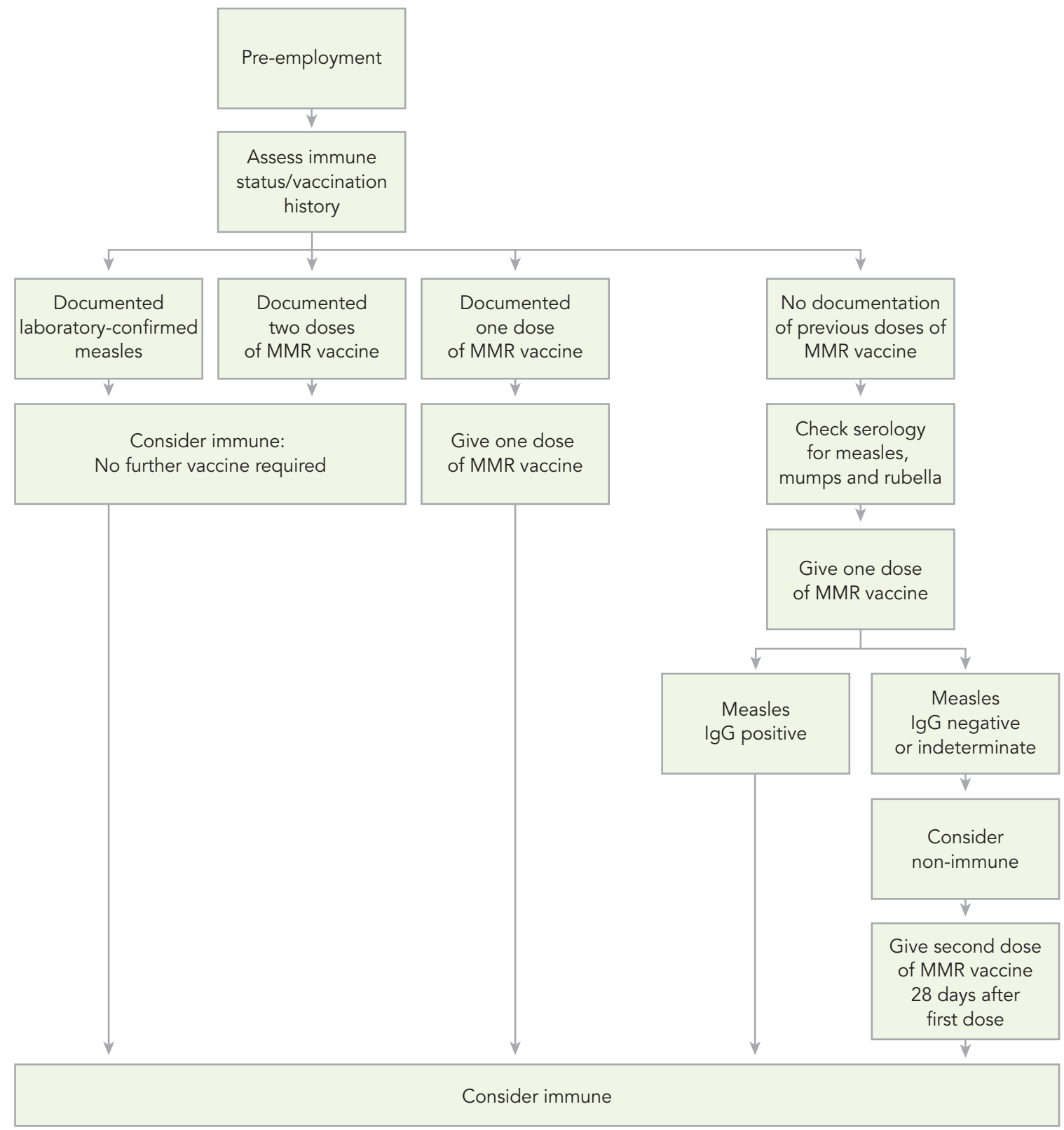


Algorithm B. Management of healthcare workers who are close contacts of a case of measles

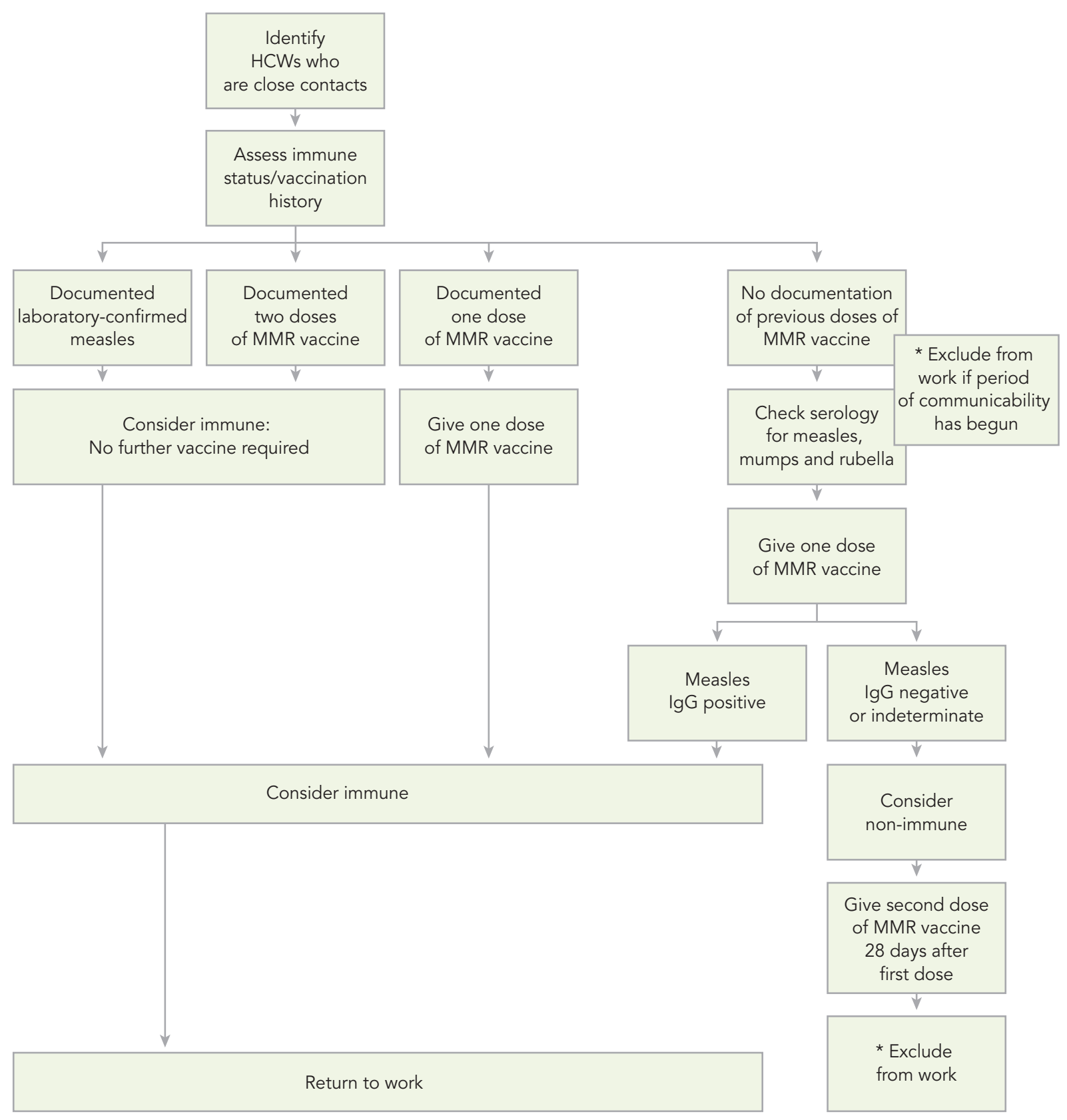

* Contacts should be excluded from the $5^{\text {th }}$ to the $21^{\text {st }}$ day after exposure 
Algorithm C. Management of patients who are close contacts of a case of measles

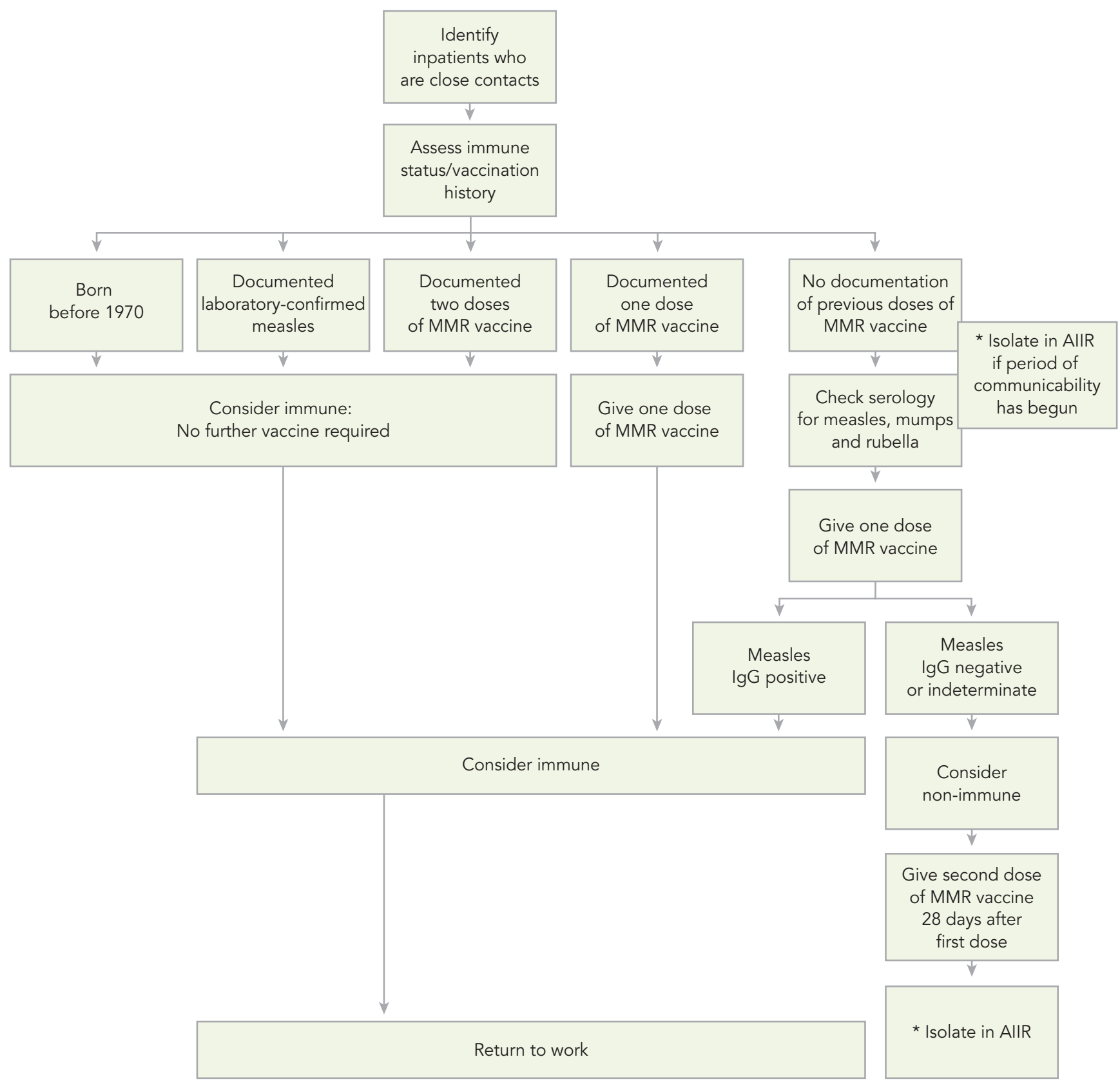

* Contacts should be excluded from the $5^{\text {th }}$ to the $21^{\text {st }}$ day after exposure 


\section{APPENDIX H. LABORATORY GUIDELINES FOR THE DIAGNOSIS OF MEASLES}

\subsection{INTRODUCTION}

The purpose of the laboratory guidelines is to provide information related to specimen collection and transportation, as well as laboratory testing methods and interpretation of laboratory test results for suspected measles cases. A comprehensive description of measles diagnostics can be found in the Manual of Clinical Microbiology (34) and more technical details can be found in (35). The information presented here is based on recent experiences in measles diagnostics in Canada and worldwide in keeping with the WHO laboratory testing guidelines (33).

\subsection{SUMMARY}

The reverse transcriptase polymerase chain reaction (RT-PCR) assay is the most sensitive and reliable test for the definitive diagnosis of measles infection, but its sensitivity can be influenced by the following:

- timing of the specimen collection in relation to onset of illness

- specimen integrity and storage conditions

- prior vaccination history

Nasopharyngeal or throat swabs collected within the first 4 days of rash onset are the preferred specimens for RT-PCR.

Urine specimens collected within the first 7 days post-rash onset are also appropriate for measles virus detection by RT-PCR.

Serological testing of an acute serum specimen for measles-specific IgM class antibody is predictive for the diagnosis of measles, but not in sporadic cases without a history of travel or epidemiological link to a confirmed measles case, for which false positive results are likely to occur. False negatives may also occur depending on the time of sample collection. Measles cases with a history of measles vaccination may not demonstrate an lgM response since these infections are not primary measles virus exposures. Collection of an acute serum specimen and a convalescent serum specimen 10 to 30 days later may show a seroconversion for IgM and/or lgG antibody in those cases in which the measles RT-PCR assay and IgM antibody were negative or indeterminate at onset of illness, thus identifying additional cases.

Collection of an acute serum specimen and a convalescent serum specimen 10 to 30 days later may show a seroconversion for IgM and/or IgG antibody in those cases in which the measles RT-PCR assay and IgM antibody were negative or indeterminate at onset of illness, thus identifying additional cases.

Serological results for previously vaccinated individuals (secondary vaccine failure) will likely not follow the paradigm associated with acute primary measles in unvaccinated individuals. Anti-measles IgM antibody response may be weak or not detectable and a rapid elevation of anti-measles lgG titre would be expected causing strong positive anti-measles lgG results in acute sera and the likely absence of a four-fold rise in IgG titre in the convalescent sera $(36,37)$.

A negative RT-PCR result is not sufficient to rule out a suspected measles case. A single lgM result, negative or positive, may not be sufficient to confirm or exclude the diagnosis, especially in sporadic cases. It is therefore important to evaluate RT-PCR, IgM and IgG seroconversion results in the context of the clinical and epidemiological data. PAHO recommends that cases be classified by a case analysis committee after review of laboratory results and epidemiology confirmation (43) (available at: www.paho.org/english/ad/fch/im/sne3102.pdf). 


\subsection{SPECIMEN COLLECTION}

\subsection{FOR VIRUS DETECTION (RT-PCR) OR ISOLATION (CULTURE)}

Nasopharyngeal or throat swab specimens should be collected using a swab approved for virus isolation. Swabs should be placed in standard viral transport media (VTM). Swabs must be left in a small volume (1 to $2 \mathrm{~mL}$ ) of VTM for a minimum of 1 hour to allow the virus to elute. Swabs may be dacron, nylon, rayon tipped either flocked or non-flocked. Calcium alginate swabs are not acceptable as they inhibit PCR reactions. Charcoal swabs or swabs in Ames media used for swabbing for bacterial pathogens such as group A Streptococcus are not acceptable. Swabs with wooden or aluminum shafts are also not acceptable.

Specimens should be collected as close as possible to the onset of rash, and within 5 days for viral isolation and 7 days for RT-PCR. Sensitivity declines sharply after this time, especially for viral isolation.

Specimens in VTM should be kept at $4^{\circ} \mathrm{C}$ and shipped on ice to the laboratory within $48 \mathrm{~h}$ from collection.

Alternatively, eluted specimens can be frozen at $-70^{\circ} \mathrm{C}$ indefinitely and sent to the lab on dry ice to prevent thawing, which would reduce the titre of infectious virus for isolation and may also reduce the sensitivity of RT-PCR.

Urine specimens. Measles virus is found in urine in exfoliated cells and it can be isolated or detected by RT-PCR with good sensitivity if urine is collected as soon as possible, and not later than 7 days, after the onset of rash.

- An ideal volume of $50 \mathrm{~mL}$ urine (minimum 10) should be collected in a sterile container.

- Specimens should be kept at $4^{\circ} \mathrm{C}$.

- As soon as possible, and no later than $24 \mathrm{~h}$, urine should be centrifuged at $2500 \mathrm{~g}$ for $15 \mathrm{~min}$ at $4^{\circ} \mathrm{C}$ and the pellet should be resuspended in 1 to $2 \mathrm{~mL}$ of a sterile physiological transport medium and sent to the laboratory on ice. The resuspended pellet can be frozen at $-70^{\circ} \mathrm{C}$ and shipped to the lab on dry Ėice to avoid thawing, which would reduce the titre of infectious virus for isolation and may also reduce the sensitivity of RT-PCR.
Oral fluid specimens. Oral fluid obtained by collecting the crevicular fluid exuding between the gums and the teeth is a non-invasive and convenient specimen that allows detection of both IgM and virus by RT-PCR. Oral fluid testing has been used with good success in low resource settings, and it is also being introduced in high resource countries. The sensitivity and specificity for IgM and virus detection approach those of serology and RT-PCR, in research settings (44), but the quality of the results varies in the field. At this time, this technique is not recommended for routine diagnosis of measles in Canada.

\subsection{SEROLOGY}

The first (acute) serum specimen should be collected as soon as possible upon presentation of measles.

For lgG testing of seroconversion, a second (convalescent) serum specimen should be collected 10 days to 30 days after the first sample.

For IgM testing, samples collected before 3 and after 28 days from the onset of symptoms may yield false negative results.

\subsection{SPECIMEN STORAGE AND TRANSPORT}

Unprocessed samples can be shipped at $4^{\circ} \mathrm{C}$ for arrival at the laboratory within 48 hours of collection. If subsequent testing is delayed, processed samples can be frozen at $-70^{\circ} \mathrm{C}$ and shipped on dry ice. Ideally, serum samples for antibody detection should be kept at $4{ }^{\circ} \mathrm{C}$ and not allowed to freeze and thaw Shipping of specimens shall be done by a Transport of Dangerous Goods (TDG) certified individual in accordance with TDG regulations. For additional information regarding classification of specimens for the purposes of shipping, consult either Part 2 Appendix 3 of the TDG Regulations or section 3.6.2 of the IATA Dangerous Goods Regulations as applicable. 


\subsection{SEROLOGY}

\subsection{IGM}

The presence of measles-specific IgM antibodies is indicative of primary/acute measles infection, when accompanied by clinical signs of measles and a history suggesting exposure to measles. Confirmation of IgM results by RT-PCR detection of the measles virus is recommended whenever possible, because false IgM result may occur as follows:

\section{Positive IgM results without acute measles infection} A positive IgM result in a case with rash and without any history of travel to endemic areas or any epidemiological link to a suspected case is most likely a false-positive. IgM testing kits may produce false-positive measles IgM results in patients with rheumatoid factor, other acute infections, with high titres of measles IgG, or seemingly at random for unknown reasons.

A measles-specific positive IgM result may occur in patients who received the MMR vaccine up to 6 weeks prior to the time of testing. There are no serological tests available to distinguish positive IgM results due to the vaccine or wild type strains of measles.

\section{Negative IgM results in the presence of acute measles infection}

Negative results may occur when the serum sample is collected before 3 days from the rash onset, when IgM may not have developed to a sufficient titre to be detected by the EIA assays.

In a population of high vaccine coverage, measles infection may, develop in previously vaccinated individuals, who may not show an IgM response.

\subsection{IGG}

The presence of measles-specific lgG is indicative of a recent or remote exposure to measles virus, either by wild type infection or by vaccination. There are no available tests to distinguish lgG antibodies due to vaccination or natural infection.

Seroconversion (i.e. negative to positive result) or a four-fold or greater rise in titre between the acute and convalescent sera is indicative of measles infection.
This does require a delay in the collection of the second (convalescent) serum sample of 10 days or more after the collection of the first (acute) serum sample. However, this may be the only way to conclusively demonstrate a measles infection when RT-PCR is not available and the IgM result is negative or unreliable.

Enzyme immunoassays (EIA) measure IgG titre as continuous OD value (sometime converted to International Units) and therefore it is important to perform end-point titrations of a sample, as opposed to a single dilution run, in order to conclusively determine the four-fold or greater difference in titres between acute and convalescent sera.

Previously vaccinated individuals (secondary vaccine failure) may represent an exception to the four-fold rise in titre paradigm in that rapid elevation of anti-measles IgG titre would be expected causing strong positive anti-measles IgG results in acute sera and the likely absence of a four-fold rise in lgG titre in the convalescent sera $(36,37)$.

Determination of the measles-specific lgG titre is used to gauge the immune status of an individual, most often for occupational reasons. The presence of measles-specific IgG, as determined using an EIA is a good indication of immunity to measles, but it does not necessarily correlate with protective neutralising antibodies measured by the gold standard, the plaque reduction neutralization test (PRNT) (38). The absence of detectable measles IgG using EIA may reflect the lower sensitivity of the EIA in comparison to a more sensitive assay, especially in young infants.

The protective level of measles IgG has been estimated between 120 (39)and 200 mIU (17), but is not precisely known.

\subsection{SUB-ACUTE SCLEROSING PANENCEPHALITIS (SSPE)}

Sub-acute sclerosing panencephalitis (SSPE) is a rare but fatal complication caused by persistent measles virus infection in the central nervous system (CNS). The virus cannot be readily detected by RT-PCR in the cerebrospinal fluid (CSF), but the relative levels of measles lgG in serum and in the cerebrospinal fluid (CSF) can be used to confirm the diagnosis, together with the characteristic clinical, neurological and pathological evidence of SSPE (45). 
This test is performed at NML and it requires paired CSF and serum specimens. Total lgG and total albumin concentrations (mg/L) in both serum and CSF must be determined and provided. Paired serum and CSF samples are tested using the Euroimmun kit for antibodies of the IgG class against measles virus in cerebrospinal fluid. The ratio of measles specific antibodies in the CSF and the serum in comparison to the ratio of total lgG or total albumin in the CSF and the serum is used to determine whether there is an indication of measles-specific antibody production in the central nervous system.

\subsection{MEASLES VIRUS DETECTION}

\subsection{REVERSE TRANSCRIPTASE POLYMERASE CHAIN REACTION (RT-PCR)}

RT-PCR is the most sensitive and the most specific test available for the confirmation of a measles infection diagnosis, provided an appropriate specimen is taken as early as possible after rash onset. Best sensitivity is achieved when the specimen is collected within 7 days from the rash onset. After that time detection of the virus is still possible, but with rapidly decreasing sensitivity.

Commercial kits for RT-PCR detection of measles do exist, but reference laboratories use in-house methods. The National Microbiology Laboratory uses two real-time RT- PCR methods targeting the nucleoprotein $(\mathrm{N})$ and the haemagglutinin $(H)$ gene, based on the methods described by Hummel et al. (46)

Detailed protocols are available from NML on request. The NML will assist laboratories who desire to implement RT-PCR by sharing protocols, training and distributing an annual molecular measles panel.

Although the analytic sensitivity of RT-PCR is between 10 and 100 genome copies, the overall clinical sensitivity is affected by pre-analytical factors (see Section 3.0 above), namely the following:

- timing of specimen collection, in relation to onset of illness

- specimen type and quality
- rapid transportation of the specimen to the laboratory

- rapid processing of specimens

- specimens for virus detection should be processed within 48 hours after sample collection. Further delays result in significant reduction in sensitivity.

- appropriate storage of specimens

- avoidance of freeze/thawing unprocessed specimens

\subsection{MEASLES VIRUS ISOLATION}

Measles virus isolation requires growing B95a or Vero/SLAM cells which are inoculated with the specimen. Cytopathic effects will appear 4 to 5 days later, at which time measles virus can be identified by immunofluorescence or RT-PCR.

Measles virus isolation is not as sensitive or rapid as RT-PCR and it is much more dependent on specimen quality and storage conditions. It also has a much longer turnaround time than RT-PCR. For these reasons, culture isolation is being used less and less frequently for primary diagnosis of measles infection. Nevertheless, it is useful to isolate measles strains from new outbreaks and sporadic cases in order to build a strain repository that can be used for finer genotyping and outbreak linkage. The NML attempts to isolate measles virus from every outbreak and sporadic case.

\subsection{MEASLES VIRUS GENOTYPING}

Measles virus genotyping is used to distinguish postvaccine rash from wild type measles infection. Genotyping is also an important surveillance tool to identify the source of importations and to link cases in outbreaks. The measles nucleotide sequence changes little during transmission within an outbreak and therefore it is a reliable tool to confirm or exclude epidemiological links. The WHO Measles and Rubella Laboratory Network recommends that national reference laboratories genotype as many cases of measles as possible, but at least $80 \%$ of sporadic cases and $80 \%$ of outbreaks. It is not necessary to genotype all cases of a large outbreak, but it is still advisable to genotype as many cases as possible to detect overlapping importation events and to study the natural history of the outbreak. 
Measles genotyping has been standardized according to WHO guidelines (47) and is available at the National Microbiology Laboratory. A portion of the nucleoprotein (N) gene is amplified by RT-PCR and the amplicon sequenced. The genotype is determined by comparison of the 450 nucleotides that code for the carboxy-terminus of the nucleoprotein to WHOstandardized genotype reference sequences. Sequences for measles samples are further analyzed by comparison of different measles strains, within the same genotype, identified in specified geographic areas. This analysis can provide confirmation of the source of importation or an epidemiological link to other cases.

NML reports all genotyping results to the WHO measles database and deposits the sequences in the MeaNS database. The MeaNS database is an invaluable resource to monitor measles molecular epidemiology around the world and health professionals can register at http://who-measles.org to access public data and reports.

For genotyping, the specimen type and handling is the same as for RT-PCR. It is advisable that an aliquot of all specimens collected for measles RT-PCR be sent to the NML for genotyping.

\subsection{INTERPRETATION OF LABORATORY RESULTS}

- A positive RT-PCR result by itself or a positive IgM result in a patient with typical clinical symptoms or with history of travel in a measles endemic area or with an epidemiological link to a confirmed case is diagnostic of measles.

- A negative RT-PCR result must be evaluated keeping in mind the time of collection of the specimen (must be collected within 7 days form the rash onset), prior vaccination history and the conditions of storage and shipping to the laboratory.

- IgG seroconversion or a fourfold increase in IgG titre in a patient who presented with rash is also diagnostic of measles, but the interpretation of an IgG increase is problematic when it is of less than fourfold (for example, in previously vaccinated patients), or it was not measured by an end-point dilution method.

- Positive IgM results in a patient with rash and without a history of exposure to measles are potentially false positives and should be confirmed by RT-PCR or evidence of seroconversion.
- An IgM positive result in a patient who received the MMR vaccine up to 6 weeks before the test may be caused by the vaccine. Seroconversion is also not a useful diagnostic test in this case. Detection of the measles virus by RT-PCR is needed to confirm the diagnosis. Genotyping is required to exclude vaccine strain infection if the vaccine was given within 2 or 3 weeks prior to the rash onset or if the patient is immunocompromised.

- A negative IgM result may occur in a measles case if the specimen was collected too early after the rash (before 3 days). A second sample can be collected 10 days later and tested for IgM, if a timely RT-PCR specimen is not available.

- A negative lgM result may occur in individuals who were previously vaccinated. In these individuals, detection of the measles virus by RT-PCR is needed.

- During outbreaks, diagnosis of measles cases is sometimes done on a positive IgM result only, on history of exposure only, or on the clinical presentation. This is however not acceptable for confirmation of sporadic cases, which should always be confirmed by laboratory data or laboratory and epidemiological data. WHO recommends that cases be classified by a case analysis committee after review of laboratory results and epidemiology confirmation (PAHO document www.paho.org/english/ad/fch/im/ sne3102.pdf)

\subsection{MEASLES TESTING AT THE NATIONAL MICROBIOLOGY LABORATORY}

The National Microbiology laboratory provides the following services:

- Measles RT-PCR (two targets)

- Measles genotyping and vaccine/wild type strain differentiation

- Serology for confirmation of SSPE

- Proficiency panels for measles IgG and IgM serology, and for molecular tests

- Culture isolation of measles virus (not for diagnostic purposes)

For more details, please consult the NML Guide to services at www.nml-Inm.gc.ca/english/guide/default.asp 


\section{APPENDIX I. STAKEHOLDER MAP}

The following is an example of a completed stakeholder map. It was developed in January 2012 by a group of PHAC experts in communications, epidemiology, surveillance and infectious disease. The stakeholder map divides stakeholders into four groups:

- Decision-makers: can include departments, branches and/or other jurisdictions that have a primary or shared role in regulating the risk.
- Transactors: The stakeholders who are most affected by the risk issue and its management and have some sort of transaction related to the risk.

- Active Interests: individuals or groups who have a stake in the issue but are not directly impacted.

- Audiences: can include general media, other government departments and interested agencies and associations who are not actively engaged in the issue or its management.

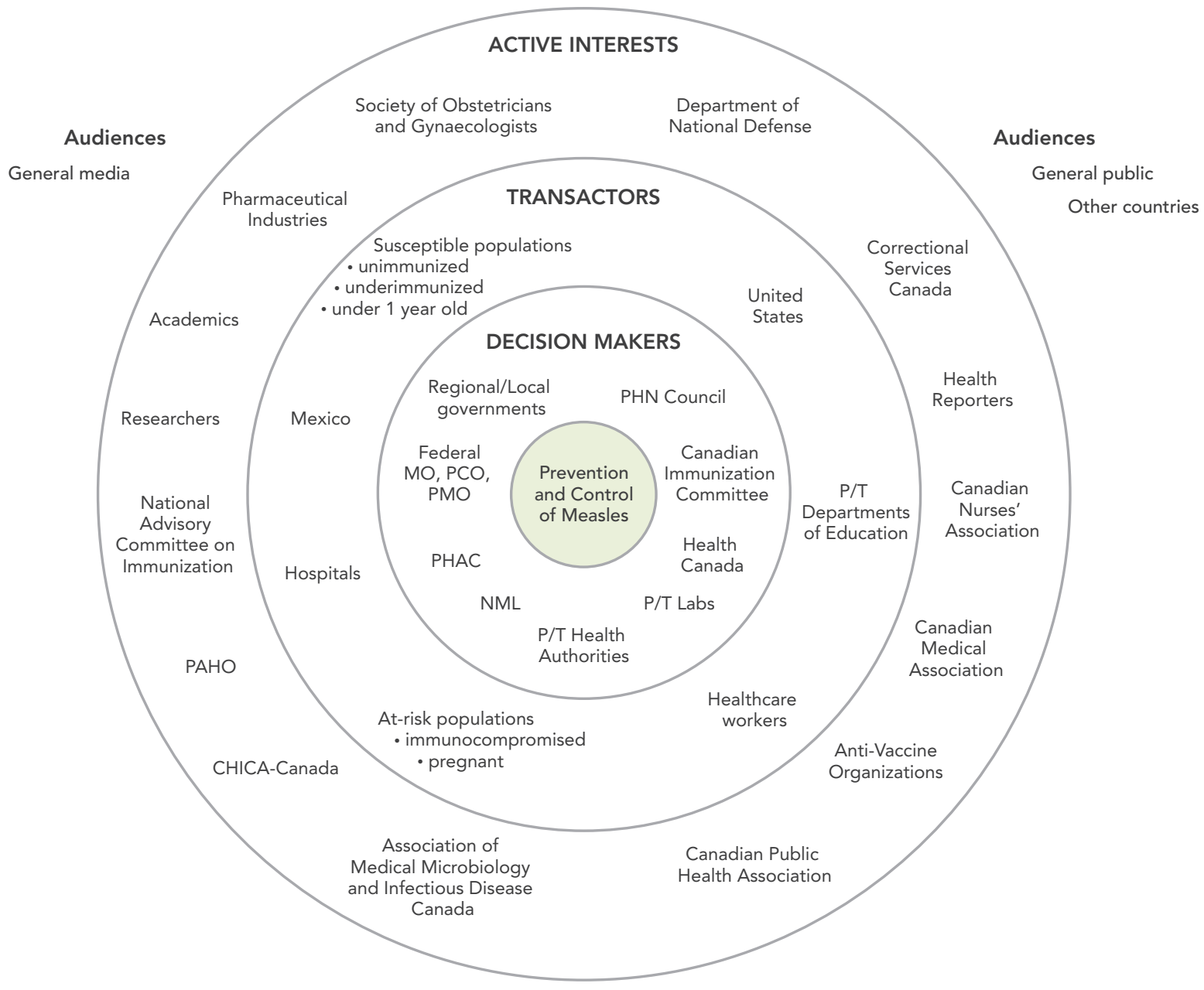




\section{APPENDIX J. \\ MESSAGE FRAMING EXAMPLE}

TOPIC: MEASLES IS A SERIOUS DISEASE.

\begin{tabular}{|c|c|}
\hline Key Message & $\begin{array}{l}\text { Measles is a highly infectious disease that affects the nose and throat. It can have serious } \\
\text { consequences. }\end{array}$ \\
\hline Evidence \#1 & $\begin{array}{l}\text { Most people recover from measles without complications, but it can be more dangerous } \\
\text { for infants, adults and pregnant women. }\end{array}$ \\
\hline Evidence \#2 & The complications of measles can include pneumonia, premature labour and low birth weights. \\
\hline Challenges \& Uncertainties & $\begin{array}{l}\text { While we know that some groups of people are particularly at-risk for complications, we can't } \\
\text { predict who will have serious complications from measles infection. We also can't predict how } \\
\text { many susceptible individuals will be affected by this outbreak. That's why individual measures } \\
\text { to prevent the spread of measles are so important. }\end{array}$ \\
\hline Personal Action & $\begin{array}{l}\text { The best way to protect yourself against measles are to: } \\
\text { - Ensure your immunizations are up-to-date; } \\
\text { - Cover your coughs and sneezes; } \\
\text { - Keep common surfaces clean and disinfected; } \\
\text { - Stay home when you're sick; and } \\
\text { - Perform hand hygiene frequently either by washing your hands with soap and water } \\
\text { thoroughly or by using alcohol-based hand rubs. }\end{array}$ \\
\hline
\end{tabular}

